\title{
Predicting Adolescents' Intentions to Engage in Fire Risk Behaviors: An Application of the Theory of Planned Behavior
}

Janelle M. Mentrikoski

Follow this and additional works at: https://researchrepository.wvu.edu/etd

\section{Recommended Citation}

Mentrikoski, Janelle M., "Predicting Adolescents' Intentions to Engage in Fire Risk Behaviors: An Application of the Theory of Planned Behavior" (2015). Graduate Theses, Dissertations, and Problem Reports. 6218.

https://researchrepository.wvu.edu/etd/6218

This Dissertation is protected by copyright and/or related rights. It has been brought to you by the The Research Repository @ WVU with permission from the rights-holder(s). You are free to use this Dissertation in any way that is permitted by the copyright and related rights legislation that applies to your use. For other uses you must obtain permission from the rights-holder(s) directly, unless additional rights are indicated by a Creative Commons license in the record and/ or on the work itself. This Dissertation has been accepted for inclusion in WVU Graduate Theses, Dissertations, and Problem Reports collection by an authorized administrator of The Research Repository @ WVU.

For more information, please contact researchrepository@mail.wvu.edu. 
Predicting Adolescents’ Intentions to Engage in Fire Risk Behaviors: An Application of the Theory of Planned Behavior

Janelle M. Mentrikoski, MS

\author{
Dissertation submitted to the \\ Eberly College of Arts and Sciences \\ at West Virginia University \\ in partial fulfillment of the requirements \\ for the degree of \\ Doctorate of Philosophy \\ in \\ Psychology
}
Christina L. Duncan, Ph.D., Chair
Aaron Metzger, Ph.D.
Elisa Krackow, Ph.D.
Natalie Shook, Ph.D.
Christa Lilly, Ph.D.

Department of Psychology
Morgantown, West Virginia
2015

Keywords: Adolescents, burn injuries, prevention, Theory of Planned Behavior

Copyright 2015 Janelle M. Mentrikoski 


\begin{abstract}
Adolescents' Intentions to Engage in Fire Risk Behaviors: An Application of the Theory of Planned Behavior
\end{abstract}

Janelle M. Mentrikoski

Burn injuries are a serious health concern for youth. In particular, adolescents are at risk for sustaining burn injuries, with recent estimates suggesting that adolescents make up nearly $30 \%$ of the burn injury cases treated in emergency departments in the United States. Despite the prevalence of burn injuries in adolescents, little research has examined possible correlates of adolescent fire-risk behavior (e.g., using accelerants to start a fire). To facilitate a better understanding of adolescent fire-risk behavior, the current study will use Ajzen's Theory of Planned Behavior (TPB) as a theoretical model. The TPB suggests that an individual's attitude towards the behavior, subjective norms or social pressure to engage in the behavior, and perceived behavioral control over the behavior together predict the person's behavioral intentions to engage in the behavior. The current study examined the utility of the TPB in explaining adolescents' behavioral intention to engage in fire-risk behaviors. In addition, this study investigated the utility of the components of the TPB to predict adolescents' behavioral intention to engage in fire-risk behaviors over and above various background variables (e.g., demographic, adolescent psychopathology). Participants were recruited from schools, clubs, and organizations in rural and urban areas in northern and central West Virginia and Kentucky. The current study included three study phases: (a) consulting with focus groups to devise content of study questionnaires; (b) piloting study questionnaires with a small sample of high school youth; and (c) using finalized questionnaires to test the model of the TPB in predicting fire-burn risk behaviors in a large sample of adolescents. Ten youth (ages 13-16) participated in the focus group discussions (Phase 1); their responses informed the content of two study questionnaires (i.e., Fire and Burn Injury Safety Questionnaire and TPB Questionnaire). Results from the pilot study (Phase 2) administration ( $n=84$; ages 13-19) suggested that both newly created measures had adequate psychometric properties. Finally, results from the third phase of the study ( $\mathrm{n}=222$, ages 13-19) indicated that the components of the TPB (i.e., attitude towards the behavior, subjective norms, and perceived behavioral control) together significantly predicted adolescents' intention to engage in fire-risk behavior. In addition, attitude towards the behavior and subjective norms emerged as significant predictors of behavioral intentions; these variables also explained the variance in behavioral intentions to engage in fire-risk behaviors over and above various control variables (e.g., SES, gender, parental monitoring). Findings from this study suggest that attitudes toward fire-risk behaviors and perceived social pressure from others may be important to target when developing fire and burn prevention programs for adolescents. 


\section{Acknowledgements}

First and foremost, I would like to thank my academic advisor and committee chair, Christina Duncan. I am eternally grateful for Christina’s unwavering support and guidance that she has provided to me over the duration of this project, as well as over the past four years. I also would like to thank the members of my committee, Aaron Metzger, Elisa Krackow, Natalie Shook, and Christa Lilly, for their time and valuable contributions to this project. Next, I would like to recognize the undergraduate research assistants and graduate students who assisted me through this project, including the members of the Pediatric Psychology Lab at West Virginia University. I am also grateful for my internship supervisors at the University of Louisville who supported me throughout the completion of this project. I would like to acknowledge all the adolescents who participated in this study. Finally, I would like to

thank my family, who provided me with endless amounts of love and support as I completed this journey through graduate school. 


\section{Table of Contents}

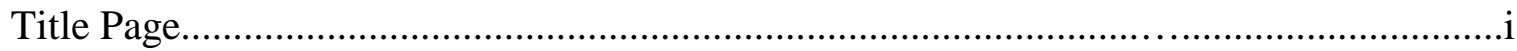

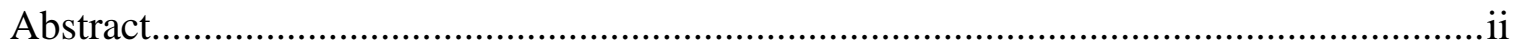

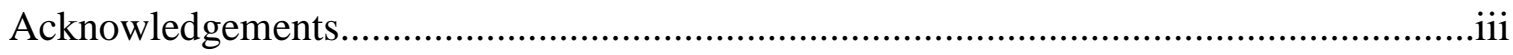

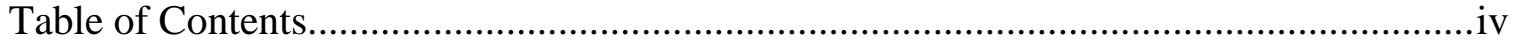

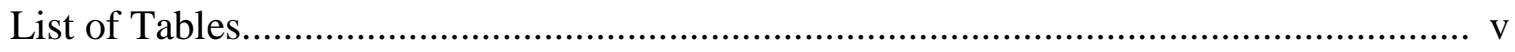

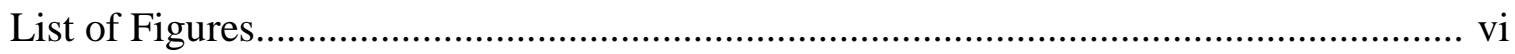

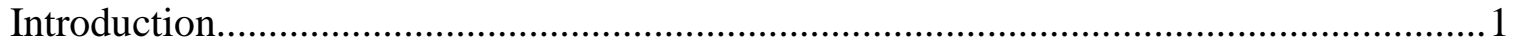

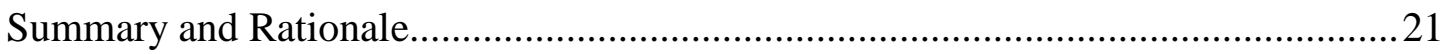

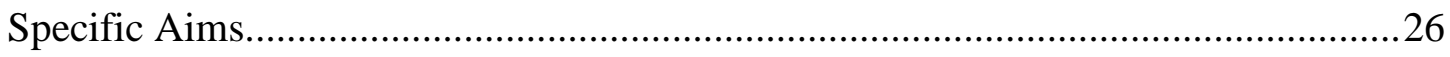

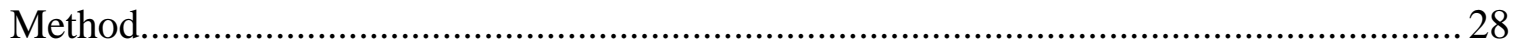

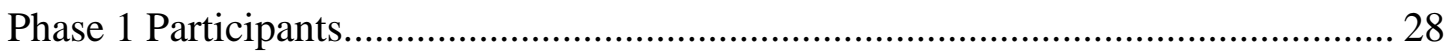

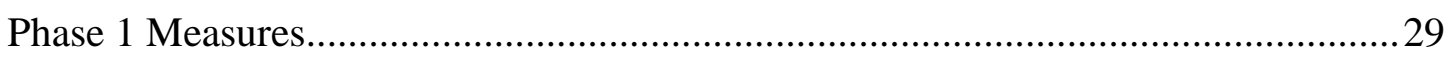

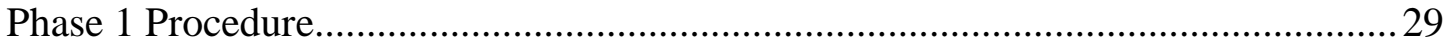

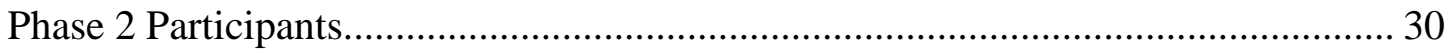

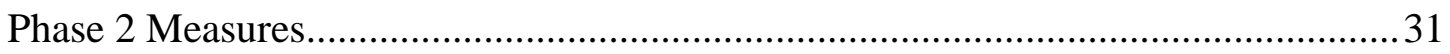

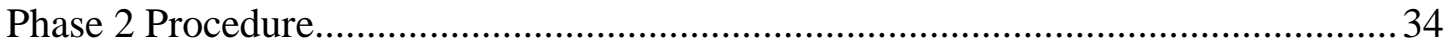

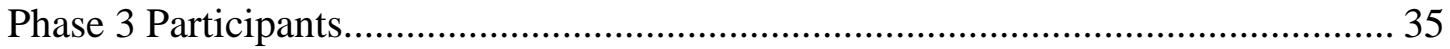

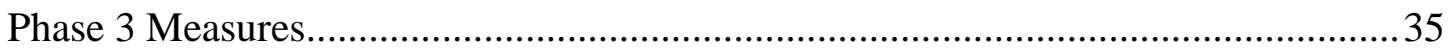

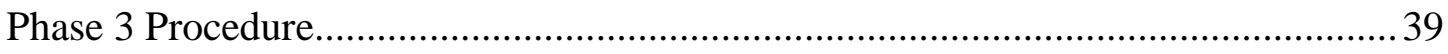

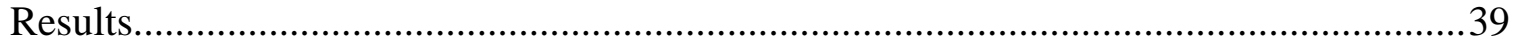

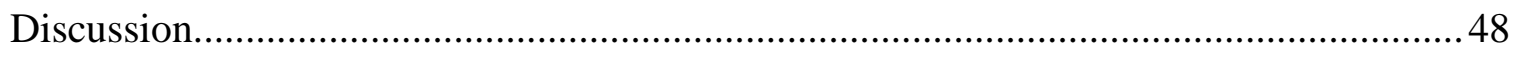

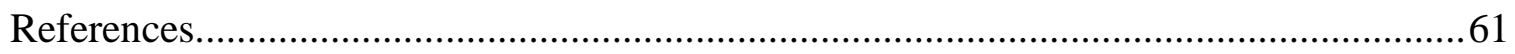

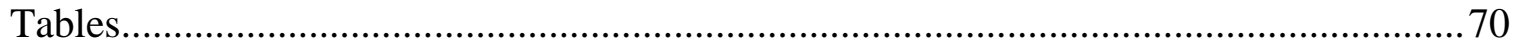

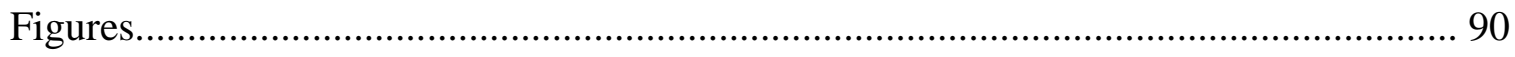


List of Tables

Table 1. Descriptive Statistics for Phase 2 Demographic Variables........................70

Table 2. Descriptive Statistics for Phase 3 Demographic Variables.......................72

Table 3. $\quad$ Frequency of Responses Elicited from Focus Group

Discussions.. .74

Table 4. $\quad$ Fire and Burn Injury Safety Questionnaire Item-to-Total

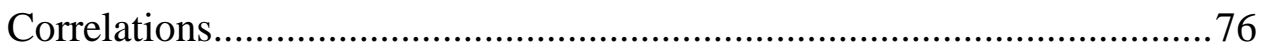

Table 5. TPB Questionnaire Cronbach Alphas and Item-to-Total

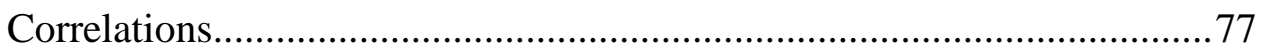

Table 6. Means and Standard Deviations of Phase 3 Study Variables.................... 79

Table 7. Means and Standard Deviations of BASC-2 Standard Scores................... 80

Table 8. Bivariate Associations among Study Variables.......................................81

Table 9. Multiple Regression Analysis Predicting Fire-Risk Behavioral

Intentions from TPB Components.................................................. 83

Table 10. Bivariate Associations among TPB Questionnaire Subscales................... 84

Table 11. Hierarchical Regression Analysis Predicting Fire-Risk

Behavioral Intentions from TPB Components while

Controlling for Age, SES, Geographic Location, and Gender................. 85

Table 12. Hierarchical Regression Analysis Predicting Fire-Risk Behavioral

Intentions from TPB Components while Controlling for BASC-2

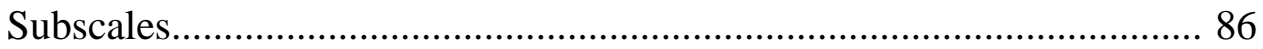

Table 13. Hierarchical Regression Analysis Predicting Fire-Risk Behavioral

Intentions from TPB Components while Controlling for Fire and Burn

Knowledge.

Table 14. Hierarchical Regression Analysis Predicting Fire-Risk Behavioral

Intentions from TPB Components while Controlling for Age and

Parental Monitoring. 88

Table 15. Hierarchical Regression Analysis Predicting Fire-Risk Behavioral

Intentions from TPB Components while Controlling for Age,

Rebellious Behavior, and Reckless Behavior 


\section{List of Figures}

Figure 1. Theory of Planned Behavior.............................................................. 90 
Predicting Adolescents’ Intentions to Engage in Fire Risk Behaviors: An Application of the Theory of Planned Behavior

Despite numerous prevention efforts, burn injuries still remain a significant health concern for children and adolescents. Every day in the United States, approximately 300 children and adolescents are treated for burn-related injuries (Centers for Disease Control, 2012). In addition, approximately 16\% of injury-related hospitalizations in youth younger than 18 years are due to burn injuries (Shields, Comstock, Fernandez, Xiang, \& Smith, 2007). Furthermore, out of 164,000 individuals treated in burn centers around the world over the past ten years, youth under the age of 20 accounted for nearly 33\% of the cases (American Burn Association National Burn Repository, 2013).

Adolescents in particular are at risk for sustaining burn injuries, due to developmental changes such as increased independence and less parental supervision. Indeed, in the United States between 1990 and 2006, out of approximately two million patients less than 20 years old treated in emergency departments for burn injuries, adolescents between the ages of 11 and 20 made up approximately $29.3 \%$ of the burn injury cases (i.e., approximately 603,000 adolescents; D’Souza, Nelson, \& McKenzie, 2009). In addition, the etiology of burn injuries changes as children age. That is, children between the ages of 0 to 5 years are most commonly burned by scald injuries (e.g., hot water, hot liquid spills; American Burn Association National Burn Repository, 2013; Peck, 2011). The higher prevalence of scald injuries in young children may suggest these injuries are the result of parental factors (e.g., problematic parental supervision; Joseph, Adams, Goldfarb, \& Slater, 2002) as well as increased motor activity and curiosity typically seen in this age range (Peck, 2011). Adolescents, on the other hand, are more commonly burned by thermal or flame injuries (American Burn Association National Burn 
Repository, 2013; Peck, 2011). One study suggested that by adolescence, 64\% of burn injuries were caused by thermal means, including burns sustained by playing with fire (12\%; Carrigan, Heimbach, \& Marvin, 1988). The higher prevalence of thermal injuries in adolescents may indicate that adolescents play a more active or causal role in their burn injuries through their own choices and poor judgment; however, little research has examined adolescents’ beliefs and attitudes that may be related to their engagement in fire-risk behavior.

Given the high occurrence of burn injuries in adolescents, it is important to examine specific predictors of fire-risk behavior in this population. Theoretical models of health behavior can be used to help conceptualize and explain this behavior in adolescents. One model, the Theory of Planned Behavior (TPB), has been applied extensively in health and injury prevention research and can be used to examine adolescents' behavioral intentions, such as their intention to engage in fire-risk behaviors (e.g., using accelerants to ignite fires). Studies have suggested that the TPB accounts for more variance when predicting individuals' behavior compared to other models of health behavior, including the Health Belief Model (e.g., Ali, Haidar, Ali, \& Maryan, 2010; Gerend \& Shepherd, 2012; Lajunen \& Rasanen, 2004). For example, Ali and colleagues (2010) compared the TPB to the Health Belief model when predicting seat belt use among adult drivers, with results suggesting that the components of the TPB accounted for more variance in seat belt use (37.9\%) compared to the variables in the Health Belief Model (15.4\%). Therefore, the TPB will provide the theoretical background for the current study.

\section{Theory of Planned Behavior}

The TPB (Ajzen 1991; 2005; see Figure 1) has been used in the health literature as a model for understanding individuals’ behavioral intentions to perform or not to perform a specified health behavior (e.g., exercise, smoke tobacco). The TPB is an updated version of the 
Theory of Reasoned Action (TRA; Ajzen \& Fishbein, 1980). Based on the TPB, behavioral intentions (and ultimately behaviors) are determined by three different components: attitude toward the behavior, subjective norm, and perceived behavioral control (Ajzen, 2005). In this theory, behavioral intention is believed to be a relatively accurate predictor of future behavior. Specifically, Ajzen (1991) explains that intentions are an individual's motivation to perform a behavior. Based on this conceptualization, it should follow that the stronger one's intention to perform a behavior, the more likely one will engage in that behavior (Ajzen, 1991). Studies have provided evidence of this. For example, a meta-analysis of studies that applied the TPB to health-related behaviors in youth and adults (e.g., smoking, cancer screenings) found that the average explained variance in behavioral intention was 0.41 , with the average explained variance in behavior equaling 0.34 (Godin \& Kok, 1996). These results suggest that the TPB components (i.e., attitude towards the behavior, subjective norms, and perceived behavioral control), on average, accounted for or explained a moderately large portion of the variance in behavioral intention to engage in various health-related behaviors and, to a lesser degree, some of the variance in actual engagement in health-related behaviors. In addition, this meta-analysis reported an average correlation of 0.46 between intention and behavior (Godin \& Kok, 1996), suggesting that behavioral intention and behavior are moderately related to one another and therefore, behavior may be predicted from behavioral intention some of the time.

The TPB is not only used to predict future behavior, but also can be used to explain why individuals engage in certain behaviors (Ajzen, 1991). Ajzen (1991) explains that an individual's beliefs related to the three components of the TPB (i.e., attitude toward behavior, subjective norm, and perceived behavioral control) will help to explain behavior. These components are broken down into three categories or underlying beliefs, each of which comprise the three 
components of the TPB: a) behavioral beliefs and outcome evaluations, which help explain one's attitude toward the behavior; b) normative beliefs and motivation to comply with the normative beliefs (i.e., the beliefs of significant others), which help explain the subjective norm; and c) control beliefs and perceived power, which are the basis of the perceived behavioral control (Ajzen, 1991). More specifically, behavioral beliefs refer to an individual’s perceived beliefs about the advantages and disadvantages of engaging in the behavior (Ajzen, 1991). Normative beliefs include beliefs about significant others who may approve or disapprove of engaging in the behavior, as well as an individuals' motivation to comply with the desire of these significant others’ (Ajzen, 1991). Finally, control beliefs refer to possible barriers or opportunities to perform the behavior; these beliefs may be based on past experience with the behavior in question (Ajzen, 1991). These three beliefs provide the basis for the three components of the TPB, which are explained in more detail in the following paragraphs.

Attitude toward the behavior is a personal factor that is defined as an individual's positive or negative appraisal of performing the specified behavior (Ajzen, 2005). This appraisal is different than the attitudes one might hold towards people or institutions and instead focuses on one’s attitudes towards actually performing the behavior in question (Ajzen, 2005). In addition to evaluating the positive or negative consequences of the specified behavior, this component also considers the relative importance of those potential consequences to the individual (Sleet, Trifiletti, Gielan, \& Simons-Morton, 2006). Attitudes included in the TPB can be classified as instrumental (e.g., engaging in the specified behavior is useful) and affective (e.g., engaging in the specified behavior is pleasant; Connor \& Sparks, 2005). When measuring attitudes in the TPB, both instrumental and affective attitudes are often included because they are known to influence behavioral intentions (e.g., Ajzen \& Driver, 1992). 
In the TPB, the subjective norm is a social influence factor that is an individual's perception of social pressure to engage or not engage in the specified behavior (Ajzen, 2005). This perception includes beliefs about others’ preferences (Sleet et al., 2006). In addition, subjective norm considers the individual's motivation to comply with other's preferences (Sleet et al., 2006). Individuals may perceive social pressure from a number of different sources (e.g., parents, significant others, peers) and the social pressure felt might vary depending on the source as well as the particular behavior under consideration (Ajzen, 2005). For example, adolescents may feel more social pressure from peers rather than their parents when evaluating their intent to consume alcohol.

Finally, perceived behavioral control is defined as an individual's self-efficacy (i.e., perceived ease or difficulty in performing the behavior) or belief in one's abilities to perform the specified behavior (Ajzen, 2005). Perceived behavioral control takes into consideration potential barriers (e.g., not having enough time to devote to exercise) that may prevent an individual from engaging in the behavior (e.g., physical activity to reduce weight) (Ajzen, 2005). It is also believed that perceived behavioral control takes into account one's past experiences with the specified behavior (Ajzen, 2005). As noted in Figure 1, perceived behavioral control not only has an indirect effect on behavior through behavioral intention, but also may have a direct effect on behavior. This conceptualization takes into consideration that in some situations, individuals will actually have volitional control over the performance of a behavior; thus, this perceived behavioral control will have a direct effect on behavior. In other situations, individuals may not have volitional control over the performance of a behavior; therefore, their perceived behavioral control will have an indirect effect on behavior through behavioral intention. Given that actual or volitional control cannot always be measured accurately, perceived behavioral control (which 
can be measured with more accuracy) can serve as a substitute or proxy of actual control (Ajzen, 2005).

To summarize, Ajzen’s TPB specifies that an individual's intentions to engage in a certain behavior are an accurate predictor of future behavior. Behavioral intentions are determined by three different components: attitude towards the behavior, subjective norms, and perceived behavior control. Each of the three TPB components is comprised of various beliefs (i.e., behavioral beliefs, normative beliefs, and control beliefs). Taking into consideration these beliefs and components, the TPB provides a theoretical framework that can be used to understand why individuals engage in certain behaviors, including fire-burn risk behaviors.

\section{Theory of Planned Behavior Applied to Burn Injuries}

The TPB can be used to explain adolescents' behavioral intentions to engage in risky fire behaviors. Applied to fire-risk behaviors, behavioral beliefs are the advantages (e.g., having fun) or disadvantages (e.g., getting burned) of engaging in fire-risk behaviors. Normative beliefs are beliefs about individuals who may approve (e.g., friends) or disapprove (e.g., fire department) of adolescents engaging in fire-risk behavior, as well as their motivation to comply with those individuals. Control beliefs are barriers or opportunities that make it easier or harder to engage in fire-risk behaviors, such as having the right resources (e.g., matches, accelerant) to start a fire or having warmer weather, which makes it more likely that the individual will be outdoors. The main components of the TPB, which include attitude towards behavior, subjective norms, and perceived behavioral control, also can be applied to fire-risk behavior. Attitude towards behavior would be comprised of the adolescents’ beliefs about engaging in fire-risk behavior. For example, youth may believe that engaging in fire-risk behaviors is enjoyable. Subjective norms are youth's perception of social pressure to engage or not engage in fire-risk behavior. In the 
case of adolescents, the social pressure from peers to engage in fire-risk behavior may be higher than the social pressure from adults. Finally, perceived behavioral control is an individual's sense of control over his or her engagement in fire-risk behaviors. More specifically, perceived behavioral control is an individual's belief in his or her abilities to perform fire-risk behaviors. For example, youth may believe that they have control in situations involving fire-risk behaviors, such as when they are at a campfire with friends. Overall, the TPB provides a thorough structure for examining fire-risk behaviors in adolescents.

\section{Studies Utilizing the Theory of Planned Behavior}

A multitude of studies in the health literature have utilized the TPB to help explain health-related behaviors. However, no studies to date have examined the application of this theory to burn injuries or fire-risk behaviors. Because of this, the subsequent review includes studies examining other health-related behaviors, but specifically in adolescents, given this is the target population.

\section{Health Behaviors in Adolescents}

Two studies by Kassem and colleagues (Kassem, Lee, Modeste, \& Johnston, 2003; Kassem \& Lee, 2004) investigated the TPB as a method to understand the consumption of soft drinks in adolescents. In their first study, the authors sampled 707 female adolescents $(M$ age $=$ 15.66, $S D=1.25$ ) from six public high schools in California (Kassem, Lee, Modeste, \& Johnston, 2003). To assess the TPB, Kassem and colleagues created a TPB questionnaire using two phases. The first phase involved focus groups with 40 female students (who had similar characteristics to the target sample) to develop the belief (i.e., behavioral, normative, and control beliefs) items for the TPB questionnaire. After meeting with the focus groups, the authors created the final 64-item TPB questionnaire. This questionnaire included items that assessed the 
three components of the TPB and the beliefs underlying these components as described in the theory. That is, items assessed the adolescents' attitudes towards soda consumption and the underlying beliefs related to adolescents’ attitudes (i.e., behavioral beliefs and outcome evaluations). Items also measured adolescents’ subjective norms and the underlying beliefs associated with their subjective norms (i.e., normative beliefs about soda consumption and motivations to comply with those beliefs). Finally, items evaluated adolescents’ perceived behavioral control over their soda consumption and the beliefs underlying this component (i.e., control beliefs and perceived power over their soda consumption).

The second phase of the study involved the administration of the final TPB questionnaire and a self-report measure of their soda consumption to participants during a class period. The authors used five separate multiple regression analyses to evaluate the ability of the TPB to predict adolescent females' soda consumption. In the first regression model, the authors included behavioral intention and perceived behavioral control as predictors of soda consumption, as the TPB model suggests that perceived behavioral control may directly predict behavior in addition to behavioral intention. In the second model, attitudes, subjective norms, and perceived behavioral control were entered as predictors of behavioral intention. The third, fourth, and fifth models evaluated the beliefs related to the three main components of the TPB. Specifically, the product of behavioral beliefs and outcome evaluations were entered in the third model as predictors of attitudes towards soda consumption. The fourth model included the product of normative beliefs and motivation to comply predicting subjective norms. Finally, in the fifth model, the product of control beliefs and perceived facilitation were entered as predictors of perceived behavioral control. When looking at the prediction of soda consumption using behavioral intention (e.g., "I intend to drink regular soda daily”) and perceived behavioral 
control (e.g., "If I chose to, I would be able to drink regular soda daily”), the results indicated that although both were positively and significantly correlated with soda consumption, only behavioral intention was found to be a significant predictor of soda consumption. Together, these two variables accounted for $28 \%$ of the variance in soda consumption. Additional results suggested that attitude, subjective norm, and perceived behavioral control were significant predictors of intention to consume soda in female adolescents and together accounted for $64 \%$ of the variance. In this model, attitude towards the behavior was the strongest predictor of behavioral intention, followed by perceived behavioral control and subjective norm. In addition, the products of the three beliefs (i.e., behavioral beliefs and outcome evaluations; normative beliefs and motivations to comply; control beliefs and perceived power) were found to significantly predict the three components of the TPB. In particular, in the attitude towards the behavior component, $49 \%$ of the variance was explained by behavioral beliefs and outcome evaluations. For subjective norms, 30\% of the variance was explained. Regarding perceived behavioral control, $24 \%$ of the variance was explained by control beliefs and perceived power.

In the second study, Kassam and Lee (2004) again applied the TPB as a theoretical framework to understand soda consumption, but this time with adolescent males. Participants included 564 male adolescents $(M$ age $=15.77, S D=1.18)$ from six public high schools in California. The procedures for this study were the same as the first study (i.e., two study phases; Kassam et al., 2003). Participants again completed the TPB questionnaire, with results suggesting that attitudes, subjective norms, and perceived behavioral control were each significant predictors of adolescent males' behavioral intention to consume soda, with $61 \%$ of the variance accounted for by the combination of these variables. In this study, the strongest predictor of soda consumption intention was attitude towards the behavior, followed by 
perceived behavioral control and then subjective norm. The components of the TPB were again significantly predicted by the various beliefs. Behavioral beliefs and outcome evaluations explained 38\% of the variance in male adolescents’ attitude towards the behavior. Normative beliefs and motivation to comply accounted for $36 \%$ of the variance in subjective norms. Additionally, control beliefs and perceived power were able to explain $22 \%$ of the variance in perceived behavioral control. Furthermore, behavioral intention and perceived behavioral control were found to be significant predictors of soda consumption and explained $15 \%$ of the variance. Similar to the results with female adolescents, behavioral intention and perceived behavioral control were positively associated with behavior but only behavioral intention was a significant predictor of soda consumption in adolescent males. Together with the results from the female adolescent study (Kassem, Lee, Modeste, \& Johnston, 2003), these results provide some evidence to support the use of the TPB in explaining soda consumption in male and female adolescents.

These studies by Kassem and colleagues (2003; 2004) demonstrated that the components of the TPB were able to account for moderate amounts of the variance in behavioral intention to drink soda, as well as account for some of the variance in actual soda consumption among adolescents. In particular, attitude towards the behavior (i.e., soda consumption) emerged as the strongest predictor of behavioral intention to drink soda. However, these studies were limited because they did not assess (and thus control for) other variables (e.g., family environment) that may be related to soda consumption. In addition, teachers selected the classes that would participate in the study; thus, selection biases may have accounted for some of the results. Furthermore, these studies examined gender differences separately rather than examining the association among gender and the TPB variables simultaneously within the same model. 
In another study, Keats, Culos-Reed, Courneya, and McBride (2007) applied the TPB to the physical activity behaviors of adolescent cancer survivors. In this study, the authors recruited 95 participants between the ages of 15 and 20 years $(M$ age $=17.37, S D=1.29)$ who were diagnosed with cancer when they were adolescents (i.e., between the ages of 11 and 19) but currently were in remission. Similar to the studies by Kassam and colleagues (Kassem et al., 2003; Kassam \& Lee, 2004), this study consisted of two phases, with the first phase eliciting the beliefs of adolescents and the second phase testing the effectiveness of the TPB components in predicting physical activity intentions and behavior. Participants in both phases of this study were mailed the questionnaires to complete. Using regression analyses, results indicated that behavioral intention and perceived behavioral control were significant predictors of physical activity in this sample of adolescents and accounted for $29.1 \%$ of the variance. Upon further examination, only behavioral intention and self-efficacy were significant predictors of physical activity (in this study, the authors used self-efficacy and perceived control as a measure of perceived behavioral control). Furthermore, the components of the TPB did a sufficient job of predicting behavioral intention, accounting for $33.7 \%$ of the variance. Only attitudes towards the behavior (i.e., instrumental and affective attitudes) were significant predictors of behavioral intentions of physical activity in adolescent cancer survivors. Finally, behavioral, normative, and control beliefs elicited from the first phase of the study were significantly and positively correlated with their respective TPB components and behavioral intention, with correlations ranging from 0.37 to 0.64 .

This study by Keats and colleagues (2007) provides additional evidence of the utility of the TPB to predict health behavior. Specifically, the components of the TPB together were able to significantly predict adolescents’ behavioral intentions to engage in physical activity. In 
addition, attitude towards the behavior emerged as a significant predictor of behavioral intention. However, the study by Keats and colleagues (2007) was limited by some of its procedures. For example, mailing study materials resulted in a response rate of only approximately 51\%. Therefore, the results may be influenced by selection biases and may not fully represent the physical activity intention and behavior among adolescent cancer survivors. Additionally, because participants completed the questionnaires in their own home, they may have had unanswered questions about some of the items included on the TPB questionnaire. Also, the sample consisted of Canadian adolescents, which may prevent the generalizability of the results to studies examining the utility of the TPB in samples of children from the United States. Finally, this study did not take into account other variables that may contribute to the association among the study constructs. Given that the variance accounted for was only moderate in size, it seems likely that other variables, such as psychopathology and parental/family variables, may improve the prediction of physical activity intentions and behaviors. Furthermore, only one component of the TPB (i.e., attitude towards the behavior) was found to be a significant predictor of behavioral intention to engage in physical activity; thus, other factors may improve the prediction of physical activity in adolescent cancer survivors.

Another study explored physical activity, in addition to eating healthy and being smokefree, in a sample of adolescents using the TPB. This study included 191 adolescents (ages 12-16) recruited from two rural and two urban intermediate schools in Eastern Canada (Murnaghan et al., 2010). Comparable to the previously reviewed studies, this study conducted a belief elicitation phase and then piloted the final TPB questionnaire before administering it to the full sample during a class period. Results from this study indicated that attitude, subjective norm, and perceived behavioral control were significant predictors of the intention to eat fruit and 
vegetables $\left(R^{2}=.50\right)$, intention to be physically active $\left(R^{2}=.56\right)$, and intention to stay smokefree $\left(R^{2}=.56\right)$. Intention was found to significantly predict self-report of the three health behaviors, with $40 \%, 41 \%$, and $25 \%$ of the variance explained in fruit and vegetable consumption, physical activity, and being smoke-free, respectively. In addition, the indirect effects of the three TPB components on actual engagement in these behaviors (i.e., the effect of attitude, subjective norms, and perceived behavioral control after proceeding through intention) were all significant for all three behaviors. Finally, 80\% of the correlations among behavioral, normative, and control beliefs and their respective TPB components were significant. Interestingly, within the normative beliefs analyses, friends were found to be most strongly related to the intentions for all three behaviors, followed by parents.

Murnaghan and colleagues (2010) noted in their discussion how the effect of the subjective norm component in predicting intention in their study was slightly larger compared to the effect of this component in other studies. The authors discussed how this component in particular may be relevant to adolescents, given the developmental shifts and the influence of peers during this age. In addition, subjective norms may be important when examining healthrelated behaviors such as the ones examined in this study (i.e., physical activity, healthy eating, and smoking). As such, continued examination of the TPB in adolescents is necessary in order to explore further age-related differences in health behaviors. Furthermore, the subjective norm component of the TPB may be particularly relevant to an adolescent sample when examining their intention to engage in fire-risk behaviors. However, like the other reviewed studies, this study was limited by the use of a Canadian sample and failed to examine other variables (e.g., demographic variables, adolescent psychopathology) that may improve prediction. 
Taken together, these studies provide evidence that the TPB can be useful in predicting various health-related behaviors in adolescents, despite some limitations in the existing research (e.g., restricted samples, lack of or limited consideration of other relevant variables). However, none of these studies sought to explain and predict adolescent fire-risk behavior, in particular.

\section{Additional Considerations Specific to Adolescent Fire-Risk Behavior}

In Ajzen’s TPB, certain variables (e.g., personality traits, education) can be conceptualized as background variables that may influence the three main components of the TPB. Although Ajzen (2005) states that these background variables are not necessarily related to an individual's beliefs and thus may not be related to an individual's behavior, Ajzen admits that the influence of background variables is an empirical question that should be evaluated by studies to further understand predictors of behavior. Consequently, the current study considers certain demographic variables, burn and fire safety knowledge, psychopathology, general risktaking behaviors, and parental monitoring as possible background variables, given that these factors are unique considerations for adolescents and for individuals who sustain burn injuries.

\section{Demographic Variables (Gender, Socioeconomic Status, Urban vs. Rural)}

Studies have suggested that the occurrence of burn injuries may vary as a function of certain demographic factors. For example, multiple research and epidemiological studies indicate that males (across all age ranges) tend to sustain burn injuries more than females (e.g., Fagenholz, Sheridan, Harris, Pelletier, \& Camargo, 2007; Mangus, Bergman, Zieger, \& Coleman, 2004; Peck, 2011). This gender difference may be due to males taking part in more high-risk behavior, engaging in occupations or household chores that involve fire (e.g., burning brush), having a higher prevalence of psychological disorders that may increase sensationseeking behaviors (e.g., ADHD, oppositional defiant disorder), or possessing a general interest in 
fire. In addition, Schwebel and Gaines (2007) suggest that the gender difference in rates of injuries could be due to biological factors, exposure opportunity, or gender socialization. Regardless, the higher prevalence of burn injuries in males is an important consideration for the current study.

In terms of socioeconomic status (SES), studies suggest that individuals from lower incomes tend to sustain burn injuries more than individuals from higher incomes (e.g., Istre, McCoy, Osborn, Barnard, \& Bolton, 2001; Peck, 2011). Possible reasons for this difference may include risks such as poor housing conditions (e.g., overcrowding, old houses), lack of safety devices (e.g., smoke detectors, fire extinguishers), possible poor parental supervision, and low parental education (e.g., Schwebel \& Gaines, 2007). Another related factor that may lead to differences in burn injury rates is one’s geographic location (i.e., urban versus rural locations). As an example, one study suggested a difference in the rates of electrical burns in a sample of children from a developing country, with children from rural areas tending to sustain electrical burns more frequently than children from more urban areas (Patil et al., 2010).

Based on these differences in burn injury rates, it was important to consider these demographic variables in the current study. Studies utilizing the TPB have indicated that demographic variables (e.g., gender differences) are not sufficient to explain more variance over and above the components included in the model (e.g., O’Callaghan \& Nausbaum, 2006); nonetheless, given the lack of research in adolescent fire-risk behavior, these demographic variables are important to examine.

\section{Fire and Burn Safety Knowledge}

Anecdotal evidence suggests that adolescents, in particular, lack knowledge about fire and burn safety. Indeed, burn and fire prevention programs in schools tend to end or decrease in 
frequency by the time youth begin to attend middle and high schools. No studies to date have examined pre-injury burn knowledge and its relation to burn injuries. Nevertheless, Tremblay and Peterson (1999) explained that people might not engage in injury preventative behaviors, such as keeping children out of the kitchen while cooking, due to the low occurrence of some injuries. As such, it could be hypothesized that people in general may not have a strong knowledge base of fire and burn safety due to the infrequent rates of burn injuries. This lack of knowledge about burn or fire safety may impact the components (i.e., attitudes, subjective norm, perceived behavior control) included in the TPB. For example, it could be that a lack of burn safety knowledge may influence adolescents' attitudes toward burn injuries in that they may not believe burn injuries are a serious concern, which in turn leads to less cautious behavior around fires. As such, assessing adolescents’ burn safety knowledge is necessary to rule out any effects of knowledge on the components of the TPB. In addition, understanding more about adolescents' burn safety knowledge may provide valuable information that can be targeted in future prevention programs.

\section{Psychopathology}

Psychopathology (e.g., behavior problems, anxiety) may be related to an increased occurrence of burn injuries. For instance, the impulsivity and attention deficits associated with attention-deficit hyperactivity disorder (ADHD) may increase the likelihood for adolescents to engage in risky fire behaviors. As an example, one retrospective study indicated that out of 1025 acute burn admissions, 44 (4.3\%) of the children between the ages of 5 and 18 years were identified as having a pre-existing diagnosis of ADHD or ADD (attention deficit disorder; Badger, Anderson, \& Kagan, 2008). In addition, 36\% of the children diagnosed with ADHD or ADD had documented histories of fire-risk behaviors, such as playing with matches, compared 
to $10 \%$ of children without a diagnosis of ADHD or ADD (Badger et al., 2008). Besides fire-risk behaviors, children in this study who were in the ADHD or ADD group tended to engage in more high-risk behaviors at the time of the injury compared to children without this diagnosis (63.6\% vs. 23.7\%; Badger et al., 2008). In another study, 54\% of children diagnosed with ADHD sustained a burn injury caused by impulsivity (e.g., playing with fire, pulling hot pan onto themselves; Thomas Ayoub, Rosenberg, Robert, \& Meyer, 2004). Finally, Mangus and colleagues found an overall ADHD rate of $13 \%$ in their chart review from one pediatric burn center (Mangus, Bergman, Zieger, \& Coleman, 2004), a rate that the authors state is higher than the prevalence of ADHD in the general population (5\%; American Psychiatric Association, 2000).

Similarly, Brehaut and colleagues (2002) suggested that children with various behavior disorders are more likely to be injured when compared to children without behavior disorders, after controlling for relevant demographic factors (e.g., gender, SES). More specific to burn injuries, a study by Piazza-Waggoner and colleagues examined the pre-injury functioning of pediatric burn survivors using a validated measure of adaptive and clinical behaviors in children (i.e., Behavioral Assessment System for Children (BASC); Piazza-Waggoner et al., 2005). In this study, 94 caregivers and their children (Mean age $=9$ ) were asked to complete the BASC based on the child's behavior prior to sustaining the burn injury. Results indicated that greater than $20 \%$ of the caregivers rated at-risk and clinically significant behavior problems in areas including hyperactivity, aggression, anxiety, attention problems, and conduct problems compared to the normative sample (Piazza-Waggoner et al., 2005). For child-report, greater than 20\% indicated at-risk and clinically significant behavior problems in anxiety and sensation seeking compared to the normative sample (Piazza-Waggoner et al., 2005). Overall, about 70\% 
of this study's sample had pre-injury behavioral difficulties in at least one clinical or adaptive area on this measure (Piazza-Waggoner et al., 2005). Additional results suggested that boys had a greater likelihood of causing their burn injury compared to girls, whose burn injuries were more likely to be due to accidental causes (Piazza-Waggoner et al., 2005). Furthermore, a nonsignificant trend emerged such that adolescents (i.e., ages 12-18) tended to be more behaviorally involved in their injuries (as opposed to sustaining their burn injuries by accidental means) compared to younger children (Piazza-Waggoner et al., 2005).

Finally, a study comparing the pre-injury functioning of 199 adults admitted to a burn unit to a normative group found that burn survivors ( $M$ age $=34.99, S D=10.56)$ had significantly elevated levels of psychological distress, anxiety, depression, loss of behavioral and emotional control, as well as overall difficulties in mental health functioning as assessed by the Rand Mental Health Inventory (Patterson et al., 2003). Interestingly, participants in this study were excluded if they had a DSM Axis I diagnosis; thus, the results were conservative and suggest that this sample of burn patients still had significant mental health concerns (that were not accounted for by a clinical diagnosis) compared to a normative group prior to sustaining their burn injuries (Patterson et al., 2003).

These studies suggest that assessing the psychopathology of adolescents in the current study is necessary, as it is important to rule out or control for symptoms that may interact with the components of the TPB or with the intention to engage in fire-risk behaviors. Without controlling for adolescents’ pre-existing behavioral problems (e.g., sensation-seeking) or disorders (e.g., ADHD), it would not be clear if adolescents' behavioral intention to engage in fire-risk behaviors is accounted for by the components of the TPB or if their behavioral intentions are accounted for by adolescents’ pre-existing behavioral problems or disorders. 
Specifically, symptoms of ADHD, sensation-seeking behaviors, and anxiety are examined based on the previous literature and the associations among these symptoms with the occurrence of burn injuries.

\section{Parental Monitoring}

Multiple studies have examined the association of parental monitoring to pediatric unintentional injuries. For example, Morrongiello, Ondejko, and Littlejohn (2004a) reported that maternal beliefs about supervision were related to their toddlers' injury risk, in that mothers who stated that they would leave their child unsupervised tended to have children who sustained more injuries. Another study by the same authors revealed that for $67 \%$ of the injuries sustained by children in their sample, mothers were not present at the time of their child's injury (Morrongiello, Ondejko, \& Littlejohn, 2004b). In contrast, there was a low rate of injuries in children when mothers provided consistent supervision (e.g., directly watching the child; Morrongiello, Ondejko, \& Littlejohn, 2004b). Moreover, Morrongiello and colleagues conducted another study where caregiver supervision was found to predict children's risk of sustaining injuries that required medical attention from a physician or a dentist (Morrongiello, Ondejko, \& Littlejohn, 2004c).

Specifically related to burn injuries, one study examined the charts of pediatric admissions to a burn unit to determine the cause of injury and the presence of caregivers at the time of injury (Carrigan, Heimback, \& Marvin, 1988). These authors created a Pediatric Risk Rating Formula, which was used to classify the circumstances surrounding the child's burn injury. Using this classification, the results indicated that at the time of burn injury, approximately $41 \%$ of children lacked or had questionable adult supervision (Carrigan et al., 1988). Although the majority (i.e., 60\%) of children included in this study were two years old or 
younger, the age range of children who sustained burn injuries without appropriate adult supervision were spread evenly across all age ranges (Carrigan, Heimbach, \& Marvin, 1988), suggesting that parental supervision may be related to the incidence of burn injuries across all youth age, including adolescents.

Most of the unintentional injury and burn literature has defined parental monitoring as actual parental presence or supervision during the time of the injury. Based on these studies, parental monitoring was thought to play an important role in protecting children from sustaining burn injuries. Although adolescence is characterized as a time when adolescents have less parental supervision (i.e., less parental presence), it was thought that some extent of parental monitoring would be related to adolescents' behavioral intention to engage in fire-risk behaviors. Parental monitoring is often defined as parental knowledge of child behavior; however, recent conceptualizations of parental monitoring suggest that other factors such as parental solicitation, child self-disclosure, and parental behavioral control may better define parental monitoring of child behavior (Kerr \& Stattin, 2000). Indeed, studies that have examined these various factors have found that child self-disclosure was predictive of delinquent behavior (Stattin \& Kerr, 2000). This conceptualization of parental monitoring was thought to be most relevant to adolescents, given that they are spending increasingly more time with their peers and less time with their parents (and thus, parents may not be physically present when youth engage in risky fire behaviors).

\section{General Risk-Taking Behaviors}

Adolescence is a time that often is associated with increased risk-taking behavior (Reyna \& Farley, 2006). For example, multiple studies have suggested that adolescents are at higher risk compared to other age groups for sexually transmitted diseases (Centers for Disease Control and 
Prevention, 2011) and motor-vehicle accidents (Centers for Disease Control and Prevention, 2010), both of which suggest that adolescents might engage in more risky behaviors. In addition, substance use typically occurs during adolescence, which may lead to negative health consequences (e.g., Bachanas et al., 2002). To date, no studies have examined the association between general risk-taking behavior in adolescents and the occurrence of burn injuries. Yet, considering general risk-taking behaviors in adolescents could help rule out any potential confounding effects of these behaviors on the components of the TPB. For example, it could be that adolescents who engage in general risk-taking behaviors (e.g., smoking, drinking alcohol) are more likely to engage in fire-risk behaviors. Alternatively, it may be that adolescents who report that they drink alcohol are more likely to engage in fire-risk behaviors due to their impaired judgment when under the influence of alcohol. In fact, Igra and Irwin (1996) suggested that risky behaviors do not occur in isolation; rather risky behaviors may co-occur (i.e., drinking alcohol may lead to engaging in unprotected sex). Therefore, general risk-taking behavior in adolescents is examined in the current study to provide a better understanding of its role in adolescents who might engage in fire-risk behaviors.

\section{Summary of the Literature and Rationale for Current Study}

Burn injuries are a serious health concern for youth. Adolescents may be at particular risk given developmental changes that occur during this time, such as increased independence and less parental supervision. Estimates suggest that approximately $29 \%$ of burn injury cases treated in emergency rooms across the United States are adolescents (D’Souza, Nelson, \& McKenzie, 2009). A theoretical model such as the TPB, which has been used extensively in the health literature to help predict and explain individual behavioral intention and behavior, can be used to help explain fire-risk behavior in adolescents. 
The TPB suggests that individuals’ beliefs can help explain and predict their behavior (Ajzen, 1991). Specifically, the theory is comprised of three components (attitude towards the behavior, subjective norm, and perceived behavioral control) that are used to predict an individual's behavioral intention to perform a given behavior. Behavioral intention is then thought to be an accurate predictor of future behavior. Taken together, the TPB specifies that an individual will intend to perform a behavior if an individual holds a positive attitude towards the behavior, believes that significant others would approve of them performing the behavior, and perceives that the behavior is under his/her control (Ajzen, 2005).

Ajzen’s TPB has been used to explain health-related behavior in adolescents. Compared to other models of health behaviors (e.g., Health Belief Model), the TPB has been shown to explain more variance (e.g., Gerend \& Shepher, 2012) and have more predictive utility in explaining health behaviors (e.g., Lajun \& Rasanen, 2004). In addition, individual studies of the TPB provide further evidence in support of using the TPB to explain health-related behavior. Two studies by Kassem and colleagues (Kassem, Lee, Modeste, \& Johnston, 2003; Kassem \& Lee, 2004) used this theory to examine soda consumption in male and female adolescents, with results suggesting that the TPB is an adequate model to predict adolescents’ behavioral intentions to drink soda. The study by Keats, Culos-Reed, Courneya, and McBride (2007) sought to examine the effectiveness of the TPB components in predicting physical activity intentions and behavior in adolescent cancer survivors. The TPB model was able to account for a significant portion of the variance in physical activity intentions (33.7\%) and actual engagement in physical activity (29.1\%). Finally, Murnaghan and colleagues (2010) examined the utility of the TPB on predicting adolescents' healthy eating, physical activity, and smoking behavior. Results from this study again supported the use of the TPB, as the TPB components were able to 
explain $50-56 \%$ of the variance in behavioral intentions. In addition, the authors from this study suggested that subjective norms may be a particularly relevant variable for adolescent populations, given the normal developmental changes that occur during adolescence. Although these studies provide support for the use of the TPB to explain adolescent health behavior, the studies failed to consider and control for other variables that may improve the prediction of adolescents' behavioral intentions and behavior. More importantly, no studies have examined the utility of the TPB in explaining fire-risk behavior in adolescents, despite the high prevalence in which burn injuries occur in this population.

The existing burn literature suggests that burn injuries vary as a function of different variables, including demographic factors, burn or fire safety knowledge, child psychopathology, general risk-taking behaviors, and parental supervision; thus, these factors may be relevant when considering predictors of behavioral intention to engage in fire-risk behaviors in adolescents. Multiple studies have indicated that males tend to sustain burn injuries more frequently than females (e.g., Fagenholz, Sheridan, Harris, Pelletier, \& Camargo, 2007; Mangus, Bergman, Zieger, \& Coleman, 2004; Peck, 2011), which may be due to a variety of factors (e.g., biological factors, general interest in fire). In addition, previous studies suggested that lower SES and geographic location may be associated with an increased risk for sustaining burn injuries (e.g., Patil et al., 2010; Peck, 2011). Moreover, little research has examined how burn or fire safety knowledge is related to the occurrence of burn injuries; nonetheless, it can be assumed that a lack of knowledge regarding fire and burn risk may increase one’s risk of sustaining a burn injury. Due to the lack of research surrounding possible predictors of burn injuries in the adolescent population, the current study seeks to provide more information on the association of 
demographic variables and burn and fire safety knowledge to burn- and fire-risk behaviors in this population.

Furthermore, psychopathology, specifically ADHD, anxiety, and sensation-seeking behaviors, has been found to be significantly related to burn injuries in children and adolescents (e.g., Badger, Anderson, \& Kagan, 2008; Piazza-Waggoner et al., 2005). However, most studies examining the psychopathology of children and adolescents who experience burn injuries are retrospective or have asked participants to report on their pre-injury functioning after sustaining a burn injury (e.g., Piazza-Waggoner et al., 2005); therefore, it is difficult to verify the accuracy of pre-injury functioning. As such, by assessing the psychopathology of adolescents and their behavioral intentions to engage in fire-risk behaviors, this study attempts to examine how adolescents' pre-existing psychopathology relates to their intention to engage in future fire-risk behaviors, which may ultimately result in burn injuries.

In addition, a lack of parental monitoring has been linked to increased injuries in children and adolescents (e.g., Carrigan, Heimback, \& Marvin, 1988). To date, studies have failed to investigate parental monitoring in relation to adolescent burn injuries, which is surprising given that adolescents tend to experience less parental supervision as they age. Just as parental supervision is important for preventing scald burn injuries in young toddlers and children, parental supervision might be equally important for preventing thermal (e.g., using accelerants to ignite fires, playing with matches) burn injuries in adolescents. Finally, general risk-taking behavior may be related to adolescents’ behavioral intention to engage in fire-risk behaviors. Studies have suggested that adolescence is a time when the occurrence of risky behaviors (e.g., underage drinking, smoking) increases (Reyna \& Farley, 2006). However, general risk-taking behavior and its relation to adolescents' engagement in fire-risk behaviors have not been 
examined. Due to the possible co-occurrence, it was necessary to control for general risk-taking in this study when examining adolescents' behavioral intention to engage in fire-risk behaviors.

It is important to note that although these factors (i.e., demographics, knowledge, psychopathology, parental monitoring, and general risk-taking behavior) are considered separately in this study, they may in fact be interrelated. In other words, some variables may serve to moderate or mediate the relation between other variables. For example, adolescents from lower SES households may have less parental supervision than those adolescents from higher SES households, which in turn could impact youth engagement in fire-risk behavior.

Nonetheless, because this is one of the first studies applying the TPB to adolescent fire-risk behavioral intentions, these factors were examined separately.

Because of the increased prevalence and risk of sustaining a burn injury during adolescence, it is important to examine potential correlates of burn- and fire-risk behavior in this population. These correlates can then be utilized in prevention programs that aim to reduce the incidence of burn injuries in adolescents. Currently, little research has examined fire-risk behaviors in adolescents and no research has evaluated prevention programs aimed to reduce burn injuries in adolescents. Therefore, it is vital to first understand the various correlates of adolescent fire-risk behavior and then use this information to inform the design of prevention programs specifically targeting these youth. For example, it may be that adolescents' attitudes towards fire-risk behaviors are strongly associated with their intention to engage in these behaviors; as such, prevention programs could be devised to target adolescents' attitudes rather than targeting general education (as is often done in prevention programs) that may be unrelated to fire-risk behaviors. Due to the lack of research on the fire-risk behaviors in adolescents, it is necessary to examine correlates using a well-established theory of health behavior. Using the 
$\mathrm{TPB}$, and taking into consideration specific variables that may be related to burn injury and firerisk behavior in adolescents (e.g., demographic variables, parental supervision), the current study evaluates the extent to which this theory is able to explain adolescent fire-risk behavior.

\section{Specific Aims and Hypotheses}

Based upon existing and relevant literature, the current study had three aims.

1. The first aim was to develop two study questionnaires; a TPB questionnaire and a fire and burn safety knowledge questionnaire. Because the TPB has not been applied to firerisk behaviors, it was necessary to first create a questionnaire. In addition, there are no questionnaires available that would be appropriate to measure fire and burn safety knowledge in adolescents and therefore, development of such a questionnaire was required. By eliciting responses from focus group participants, it was anticipated that relevant items for a TPB questionnaire and a fire and burn safety knowledge questionnaire could be developed.

2. The second aim of the study was to examine the psychometric properties of the created TPB and fire and burn safety knowledge questionnaires.

3. The third and final aim was to investigate the degree to which the components of the TPB (i.e., attitudes, subjective norms, and perceived behavioral control) predict adolescents’ intention to engage in fire-risk behaviors. As suggested by the previously reviewed studies, it was hypothesized that all three components combined would account for a significant portion of the variance in adolescents’ intention to engage in fire-risk behaviors. It was also hypothesized that all three components individually would be significant predictors of adolescents' behavioral intention to engage in fire-risk 
behaviors. Specifically, based on previous literature, it was anticipated that attitudes and subjective norms would be the strongest predictors of behavioral intention.

a. In addition, to further understand the underlying beliefs of the TPB components (i.e., attitude towards the behavior, subjective norms, and perceived behavioral control), this aim sought to examine the extent to which individuals’ beliefs (i.e., behavioral beliefs and outcome evaluations; normative beliefs and motivation to comply; control beliefs and perceived power) correlate with the respective components of the TPB. It was hypothesized that these beliefs will significantly and positively correlate with the respective constructs of the TPB (e.g., behavioral beliefs and attitude towards the behavior will significantly and positively correlate).

b. Additionally, this aim sought to determine the extent to which the TPB components (i.e., attitude towards the behavior, subjective norm, perceived behavioral control) are able to predict adolescents' intention to engage in fire-risk behaviors over and above the influence of certain background variables (i.e., gender, SES, geographic location, burn and fire safety knowledge, parental monitoring, general risk-taking behavior, and adolescent psychopathology). It was hypothesized that after controlling for these variables, the components of the TPB would sufficiently explain the variance of adolescents’ intention to engage in firerisk behaviors over and above the potential influence of the background variables. As predicted previously and based on previous literature, it was thought that attitude towards behavior and subjective norms would be the strongest predictors 
of adolescents' behavioral intention to engage in fire-risk behaviors after controlling for the above stated covariates.

\section{Method}

\section{Phase 1: Measure Development Via Focus Groups Participants}

To comprise focus groups, participants (ages of 13-18 years) were recruited from high schools and clubs (i.e., 4-H, Boys and Girls Club) in northern and central West Virginia. Participants were excluded from the study if they were non-English speaking or if they had a significant cognitive impairment (e.g., intellectual disability) that precluded them from completing the study questionnaires with minimal assistance.

The focus group sample consisted of ten participants between the ages of 13 and 16 years $(M$ age $=14.60, S D=0.97)$. All ten adolescents who were approached agreed to participate, resulting in a response rate of $100 \%$. Six (60.00\%) of the participants were male and four (40.00\%) were female. The majority of youth were Caucasian (90.00\%), while one participant was bi-racial. Four participants were in eighth grade at the time of the study, two were in ninth grade, and four were in tenth grade. In terms of academic performance, the majority of youth in this sample indicated that they receive mostly A's and B's in school (80.00\%). Most of the participants endorsed sustaining a burn injury at some point during their lives (90.00\%); however, none required hospitalization for their burn injuries. Youth in this sample mostly came from intact families (i.e., both biological parents are married and living in the same home; 70.00\%) and the majority of families were well-educated (i.e., completed undergraduate college or more; $80.00 \%)$. 


\section{Measures}

Participants completed a Participant Information Form (described in Phase 3 methods) to collect relevant demographic information and a semi-structured interview.

\section{Semi-Structured Interview}

A semi-structured interview was conducted to elicit fire and burn safety knowledge and the TPB beliefs. Participants responded to open-ended questions that asked them to describe some activities they engage in that might involve fire risk (e.g., burning brush or trash, job environments). Participants also responded to open-ended questions regarding any fire or burn prevention strategies or knowledge they might use in the fire-risk situations they previously described. Questions to assess the TPB beliefs asked about the positive and negative outcomes of engaging in this behavior (i.e., behavioral beliefs), individuals who may approve/disapprove of engagement in this behavior (i.e., normative beliefs), and factors that might prohibit or facilitate engaging in this behavior (i.e., control beliefs). Questions assessing the TPB beliefs were adapted from Rhoades, Kridli, and Penprase (2011) and Francis and colleagues (2004).

\section{Procedure}

Members of the research team approached potential participants and their parents/caregivers. A brief description of the study, as well as participant responsibilities, was provided to the participants and their parents/caregivers; consent and assent were reviewed with interested participants. Once consent/assent was obtained, research team members met with participants individually or in small focus groups (i.e., 2-3 participants) to administer the Participant Information Form and the aforementioned semi-structured interview. ${ }^{1}$ Participation

\footnotetext{
${ }^{1}$ Copies of semi-structured interview questions and measures used in this study are available upon request from Dr. Christina Duncan (christina.duncan@mail.wvu.edu).
} 
in the focus group took approximately 45 minutes. For their time and input, participants each were reimbursed with $\$ 10$ gift cards.

After meeting with the focus groups, the Fire and Burn Injury Safety Questionnaire and the TPB Questionnaire were created. All focus group interviews were audio-recorded and subsequently transcribed by research team members. Two independent research team members then coded the transcribed interviews. For the purposes of this study, frequencies of item responses were calculated; responses were ordered from most frequently endorsed to least frequently endorsed.

\section{Phase 2: Pilot Administration of Measures}

\section{Participants}

Participants between the ages of 14 and 19 years were recruited to pilot the newly created Fire and Burn Injury Safety Questionnaire and the TPB Questionnaire. Approximately half of the participants were recruited from Morgantown High School in Morgantown, WV (small town school, $n=40$ ) and the other half were recruited from Atherton High School in Louisville, KY (urban school, $n=44$ ). The response rate at Morgantown High School was 90.1\%, while the response rate at Atherton High School was 43.14\%. Participants were excluded from the study if they were non-English speaking or if they had a significant cognitive impairment (e.g., intellectual disability) that precluded them from completing the study questionnaires with minimal assistance. Participants also were excluded if they previously participated in Phase 1 of this study. A total of 84 youth $(M$ age $=16.25, S D=1.46)$ were included in this phase of the study. Demographic information for this sample is provided in Table 1. 


\section{Measures}

Participants completed a Participant Information Form (described in Phase 3 methods), the Fire and Burn Injury Safety Questionnaire, and the TPB Questionnaire.

Fire and Burn Injury Safety Questionnaire (FBISQ). This questionnaire was designed for the purpose of this study to assess youth's knowledge of common fire and burn safety. Items were developed after meeting with participants during the Focus Group phase (Phase 1). Participants were asked to respond to various open-ended questions and brief vignettes. Given that answers may represent a range of fire and/or risk behavior, this measure allowed participants to respond freely to the questions and vignettes rather than prompt or clue respondents with multiple-choice items.

Responses were scored using a coding scheme. A rater assigned a score to each item response: 1 = high risk, 2 = some risk, and $3=$ no/minimal risk. Summing item scores across all responses yielded a total score; higher total scores indicated more fire and burn safety knowledge.

TPB Questionnaire. This questionnaire was designed for the purposes of this study to examine youth’s attitudes, social norms, and perceived behavioral control towards fire-risk behavior. Items for this measure were developed after meeting with focus groups and were formatted based on previously published TPB measures (e.g., Keats, Culos-Reed, Courneya, \& McBride, 2007) and using the manual by Francis and colleagues (2004). That is, the previously published measures and the manual helped inform the item stems, response formats, and scoring approach for the current study’s TPB questionnaire. However, the response formats were changed to 4-point scales (i.e., "very easy,” “easy,” “very hard,” “hard”), rather than 7-point scales (i.e., "not at all” to "very much”), to facilitate ease in responding. 
As a measure of past behavior, participants were asked first to indicate fire-risk behaviors that they may have engaged in at least one time in their lives. Participants then were asked to respond to items that assess the three beliefs (i.e., behavioral, normative, and control beliefs) and the main constructs of the TPB (i.e., behavioral intention, attitude, subjective norm, and perceived behavioral control) with regard to those reported fire-risk behaviors.

Section A: Behavioral intentions. Some authors suggest using more general language when assessing behavioral intention for behaviors that are not socially desirable (Parker, Manstead, Stradling, Reason, \& Baxter, 1992). Therefore, because engaging in fire-risk behaviors is considered not to be socially desirable, the items used to measure behavioral intention were worded more generally (e.g., "I think I might engage in a fire behavior(s) at least one time over the next three months.”). Behavioral intention was assessed with three items. Participants responded on a 4-point scale ( 0 = strongly disagree; 3 = strongly agree). Based on previous literature (e.g., Francis et al., 2004), items were averaged to yield a total behavioral intention score, with higher scores indicating stronger behavioral intentions to engage in fire-risk behaviors.

Section B: Behavioral beliefs and outcome evaluation items. For behavioral belief items, participants responded to six items that evaluated the likelihood of various outcomes (e.g., "If I engage in fire behavior, I will get burned.”). Participants rated their responses on a 4-point scale, ranging from 0 (very unlikely) to 3 (very likely). In addition, participants rated the desirability of the various outcomes (i.e., outcome evaluation) for each belief, using a 4-point scale ( 0 = very undesirable; 3 = very desirable). A total behavioral beliefs score was calculated by first multiplying the beliefs total score by the respective outcome evaluations and then summing the products, with higher scores indicating more positive attitudes towards of fire-risk behaviors. 
Section C: Normative beliefs and motivation to comply items. To measure normative beliefs, participants were asked to rate the extent to which important others would approve/disapprove of them engaging in fire-risk behaviors (e.g., "My parents would of me engaging in fire behaviors.”). Participants responded using a 4-point scale ( 0 = strongly disapprove; 3 = strongly approve). Participants also were asked to rate how motivated they are to comply with the desires of their important others. Participants responded to these items using a 4-point scale $(0=$ strongly disagree; 3 = strongly agree $)$. A total normative beliefs score was calculated by summing the products of the normative belief items with the respective motivation to comply items, with higher scores reflecting more social pressure to engage in fire-risk behaviors.

Section D: Control beliefs and perceived power items. Participants responded to items that assessed factors (e.g., "When I am engaging in fire behaviors, I have the right resources or what I need.”) influencing participants' engagement in fire-risk behaviors using a 4-point scale (0 = very false; 3 = very true). Participants also responded to questions measuring the perceived power of the factors (e.g., "Having the right resources or access to the things I need makes it to engage in fire behaviors.”) with a 4 -point scale $(0=$ very hard; $3=$ very easy). A total control beliefs score was calculated by first multiplying the scores from the control beliefs and perceived power items and then summing the resulting products, with higher scores indicating more perceived control over engaging in fire-risk behaviors.

Section E: Attitude toward behavior. Six items were used to examine both instrumental and affective attitudes towards engaging in fire behaviors. Participants rated their responses using a 4-response semantic differential scale that included a variety of bipolar adjectives (e.g., very 
bad/very good). A total attitude score was calculated by summing the item scores, with higher scores indicating more positive attitudes towards fire-risk behaviors.

Section F: Subjective norms. To assess subjective norms, four items were used that measured the opinions of important others in general on adolescents' behavioral intention to engage in fire-risk behaviors. Participants responded on a 4-point scale for each item $(0=$ strongly disagree; 3 = strongly agree). A total score was calculated by summing the item scores, with higher scores indicating higher ratings of social pressure.

Section G: Perceived behavioral control. Finally, three items were used to evaluate perceived behavioral control. These items assessed self-efficacy and perceived controllability. Participants responded to these items using a 4-point scale for each item $(0=$ strongly disagree; 3 = strongly agree); scores were summed to obtain a total perceived behavioral control score, with higher scores indicating higher ratings of perceived self-efficacy and controllability.

\section{Procedure}

Research team members approached potential participants during their class periods. A brief description of the study, as well as participant responsibilities, was reviewed with the classes. Participants 17 years and younger were given a parent consent form (with a recruitment letter describing the study) and an adolescent assent form; participants 18 years and older were given an adolescent consent form. Participants were instructed to complete the consent/assent forms and return to the research team. A few days later, students having provided written assent/consent (as mentioned above) completed the study measures during a class period. Researchers delivered brief instructions about how to complete the study questionnaires and were available to respond to questions. The questionnaires took participants approximately 20 to 
30 minutes to complete. For their time and input, participants each received a lottery ticket to be entered into a drawing to win one of 10, \$20 gift cards.

\section{Phase 3: Data Collection for TPB Model}

\section{Participants}

Participants between the ages of 14 and 19 years were recruited for the full data collection phase. Approximately half of the participants were recruited from Morgantown High School in Morgantown, WV (small town school, $n=83$ ) and Elkins High School in Elkins, WV (rural school, $n=49$ ), while the other half were recruited from Atherton High School in Louisville, KY (urban school, $n=90$ ). The response rates for each of the three schools were as follows: 46.11\% at Morgantown High School; 42.24\% at Elkins High School; and 55.21\% at Atherton High School. Participants were excluded from the study if they were non-English speaking or if they had a significant cognitive impairment (e.g., intellectual disability) that precluded them from completing the study questionnaires with minimal assistance. Participants also were excluded if they previously participated in Phase 1 or Phase 2 of this study. A total of 222 youth $(M$ age $=15.23 ; S D=1.06)$ were included in this phase of the study. Demographic information for this sample is provided in Table 2.

\section{Measures}

Participants completed a series of study questionnaires, including finalized versions of the Fire and Burn Safety Injury Questionnaire (Cronbach’s alpha $=0.49$ ) and the TPB Questionnaire (range of Cronbach’s alpha $=0.68$ to 0.92 across components and behavioral intentions, 0.47 to 0.74 across beliefs), as well as the Participant Information Form, the Behavior Assessment Scale for Children ( $2^{\text {nd }}$ Edition), an adapted Parent/Caregiver Monitoring Scale, and a modified version of the Adolescent Risk-Taking Questionnaire. 
Participant Information Form (PIF). The PIF was created specifically for the purpose of this study and included relevant demographic (e.g., age, gender, SES) information. Urban/suburban versus rural categories were determined based on the participants’ hometown. For the purposes of this study, and based on methods used by the United States Census, rural status was applied to those individuals who report residing in a hometown of at least 2,500 but less than 50,000 residents (U.S. Census Bureau, 2013). Urban status was assigned to those individuals living in communities larger than 50,000 individuals. Based on these methods, rural status was assigned to participants from Morgantown, WV and Elkins, WV and urban status was assigned to participants from Louisville, KY.

Socioeconomic status (SES) was calculated from parental education levels and occupation titles, which were reported by adolescent participants on the Participant Information Form. Using the Hollingshead Four-Factor Index of Social Status (Hollingshead, 1975), parental education was rated on a 7-point scale, ranging from 1 (less than $7^{\text {th }}$ grade education) to 7 (professional or graduate training. Occupations were rated on a 9-point scale, ranging from 1 (e.g., farm laborers, students, housewives, maids) to 9 (e.g., higher executives, professors). Both scores are weighted (i.e., education multiplied by 3; occupation multiplied by 5) and summed; in the case of dual-earners in the household, SES was averaged across both earners. Scores using the Hollingshead Index range from 8 to 66, with higher scores reflecting higher SES.

\section{Behavior Assessment System for Children - $2^{\text {nd }}$ Edition: Self-Report of Personality-} Adolescent (BASC-2: SRP-A, Reynolds \& Kamphaus, 2006). The BASC-2: SRP-A is a selfreport questionnaire in a standardized, comprehensive, multi-informant rating system for assessing maladaptive and adaptive behaviors and personality in youth ages 2 through 21 years. The BASC-2: SRP-A yields scores on composite scales (e.g., Externalizing Problems) and 
subscales (e.g., Anxiety), as well as validity scores that detect overly negative/positive responses or invalid responding. Raw scores are compared to same-aged boys and girls in the normative sample to yield standard scores $(M=50 ; S D=10)$ and percentile ranks. Participants are asked to complete general statements (e.g., "I like who I am”) using a "true” or "false” rating system. They also are asked to complete item stems (e.g., "I am afraid of a lot of things”) using a fourpoint Likert scale ( 0 = never; 3 = almost always). For the purposes of this study, age- and gender-based T-scores from the Anxiety, Sensation-Seeking, Attention Problems, and Hyperactivity subscales were used, with higher scores indicating more problematic behaviors.

The BASC-2 is a well-validated measure and has been shown to have good psychometric properties as a psychosocial screening tool (Reynolds \& Kamphaus, 2006). Specifically, the BASC-2 has been shown to have satisfactory internal consistencies (i.e., coefficient alphas) acoss all subscales, including the Anxiety (0.86), Sensation-Seeking (0.69), Attention Problems (0.78), and Hyperactivity (0.74) subscales (Reynolds \& Kamphaus, 2006). In addition, the validity of these subscales is supported by the significant and moderate correlations among these subscales and similar items from the Achenbach System of Empirically Based Assessment Youth SelfReport and the Conners-Wells’ Adolescents Self-Report Scale (Reynolds \& Kamphaus, 2006).

Parent/Caregiver Monitoring Scale. This 42-item scale was designed for the purposes of this study to assess parental/caregiver monitoring. Items were adapted from previously established scales of family rules and parental behavioral control (e.g., Parental Restrictive Control Questionnaire, Smetana \& Daddis, 2002), parent solicitation, and adolescent disclosure (Smetana, Metzger, Gettman, \& Campione-Barr, 2006), all of which are components of parental monitoring. Participants responded using a 5-point Likert-type scale, with a score of 0 corresponding to 'never' and a score of 4 corresponding to 'always.' In this study, total scores 
(i.e., sums) were calculated for the parental solicitation, adolescent self-disclosure, and parental behavioral control items, with higher scores indicating more parental solicitation, adolescent self-disclosure, and parental behavioral control, respectively. With the current sample, Cronbach's alphas for each of the three subscales were acceptable: parental solicitation (0.85); child self-disclosure (0.86); and parental behavioral control (0.89).

Adolescent Risk-Taking Questionnaire. The Adolescent Risk-Taking Questionnaire (ARQ; Gullone, Moore, Moss, \& Boyd, 2000) is a 22-item checklist that assesses adolescent thrillseeking (e.g., inline skating), rebellious (e.g., underage drinking), reckless (e.g., drinking and driving), and antisocial (e.g., overeating) behaviors. Using a 5-point scale, participants rate how often they engage in the described behaviors, ranging from 0 (never) to 4 (very often). For the purposes of this study, only items included in the Rebellious (5 items) and Reckless Behavior (5 items) subscales were administered, as thrill-seeking behaviors were sufficiently measured by the sensation-seeking items in the BASC-2 and the antisocial behavior items did not seem relevant to the current study aims. Consequently, the questionnaire was reduced to 10 items to index rebellious and reckless behaviors. Total scores for these subscales are computed by averaging scores for each subscale, with higher scores indicating more rebellious or reckless behavior. The $A R Q$ has demonstrated appropriate psychometric properties, with Cronbach's alphas greater than 0.80 for both the reckless and rebellious subscales (Gullone, Moore, Moss, \& Boyd, 2000). In addition, the $A R Q$ was found to have a meaningful factor structure (Gullone, Moore, Moss, \& Boyd, 2000). In the current study, Cronbach's alpha for the Rebellious Subscale was 0.86, while the Cronbach’s alpha for the Reckless Subscale was 0.54 . 


\section{Procedure}

The consent/assent and data collection process for this phase followed that reported for Phase 2. For the participants recruited from both Morgantown and Elkins High Schools, consent/assent forms were distributed to students to take home to their parents and return to the teacher; participants completed measures a few days later. Participants from Atherton High School completed study measures one day after returning their consent/assent forms. The questionnaires took participants approximately 25 to 45 minutes to complete during their class period. For their time and input, participants each were entered into a drawing to win one of 20, \$20 gift cards.

\section{Results}

An a prior power analysis was conducted to determine how many participants would be required to sufficiently power this study in its third phase. Based on previous TPB literature, which suggested a medium effect size (e.g., Keats, Culos-Reed, Courneya, \& McBride, 2007), an effect size of 0.15 was used to conduct a power analysis. Using a power level of 0.80 and an alpha level of 0.05 , it was determined that the current study would require a minimum of 103 participants.

\section{Aim 1}

Aim 1 sought to develop two study questionnaires; a TPB questionnaire and a fire and burn safety knowledge questionnaire. To address this aim, frequencies of answers from the focus groups interviews were calculated. Items that were most frequently endorsed by participants (i.e., endorsed by $20 \%$ or more of the focus groups) were included in the final TPB Questionnaire.

A total of five focus groups were conducted with participants. The groups were composed of the following number of participants: two groups included one participant each (ages 14 and 15, respectively), one group included two participants (both 15 years old), and two 
groups included three participants each (one group was composed of 13 to 14 year olds, while the other group consisted of 14 to 16 year olds), for a total of 10 participants. An undergraduate research assistant conducted the focus group that consisted of two participants; the principal investigator proctored all other focus groups. Participants in the 2- and 3-person groups knew one another (i.e., they either were at the same after-school club or they went to the same school), with the exception of one participant who attended a different high school. Participants in the groups (i.e., with more than one participant) were able to discuss each item as a group, as well as provide individual responses to items. In some instances, a participant in the group would provide a response that the rest of the group would agree/disagree with.

Participants were first asked to list behaviors they engaged in that put them at risk for burn injuries. The most frequently cited behaviors are presented in Table 3. The behaviors that had the most risk (i.e., they were reported more frequently by the participants) for burn injuries (e.g., burning objects, leaving food unattended on the stove) were then included on the first page of the TPB Questionnaire; behaviors such as straightening hair and cooking (in general) were deemed less risky and thus were not included. Participants were then asked about the advantages/disadvantages of as well as various outcomes that would be expected when engaging in fire-risk behaviors. The most frequently endorsed items (i.e., at least 20\% of the participants) are presented in Table 3; these topics were used to create items for Section B (behavioral beliefs) of the TPB Questionnaire. Next, participants responded to questions about others who would approve/disapprove of them engaging in fire-risk behaviors, as well as who would serve as a resource to learn more about fire-risk behaviors. The top answers are presented in Table 3 and were used to create items for Section C (normative beliefs) of the TPB Questionnaire. Participants also were asked about things that might make it easier or harder for them to engage 
in fire-risk behaviors (see Table 3). These responses were then used to develop items for Section D (control beliefs) of the TPB Questionnaire. Finally, participants were asked to provide adjectives to describe engaging in fire-risk behaviors (see Table 3); these responses informed Section E (attitude towards behavior) items on the TPB Questionnaire. All items on the TPB Questionnaire were worded using examples of TPB questionnaires from the literature (e.g., Francis et al., 2004).

To create items for the Fire and Burn Injury Safety Questionnaire, participants were asked about their knowledge of common fire and burn safety tips. Of note, many participants did not know how to properly put out a grease fire; many participants (70\%) responded with "using flour” or “do not use water.” Participants did mention stop, drop, and roll (60\%) and feel the doorknob before exiting a room during a fire (40\%). Thirty percent of participants stated that smoke detectors should be checked once a year, while another $30 \%$ of participants stated that you should not put gasoline on fires. Finally, 30\% of participants stated that you should wear oven mitts when cooking. Other responses ranged from unplugging appliances when not in use, stomping out coals in the fire pit, and spread dirt or sand over fire pit when done. These responses were used to inform items on the Fire and Burn Injury Safety Questionnaire. For example, as most participants did not know how to safely put out a grease fire, an item was created that asked about how to properly do this.

\section{Aim 2}

The second aim of the study was to examine the initial psychometric properties of the created TPB Questionnaire and the Fire and Burn Injury Safety Questionnaire. This aim was addressed by calculating Cronbach’s alpha and item-to-total correlations to assess reliability. 
The 15-item Fire and Burn Injury Safety Questionnaire was found to have satisfactory levels of internal consistency as assessed by Cronbach’s alpha (0.66). The item-to-total correlations for this measure are presented in Table 4. These correlations revealed that items on the FBISQ had low to moderate correlations with the total score. Upon further examination, Item 8 (“...how should you put out a grease fire?”) was found to have minimal correlation with the total score. In addition, Cronbach’s alpha would be improved to 0.69 if Item 8 were deleted. However, the improvement in Cronbach’s alpha was minimal and this item was considered a critical item on the scale; thus, this item was retained.

Because various subscales from the 50-item TPB Questionnaire would be utilized in Phase 2 analyses, the psychometric properties of these subscales were examined individually. The Cronbach's alphas for each subscale are presented in Table 5. As evidenced by these values, the subscales of the TPB Questionnaire demonstrate satisfactory levels of internal consistency, with the exception of the Perceived Behavioral Control subscale. Upon further examination, it was determined that with the deletion of Item 49 ("The decision to engage in fire behaviors is beyond my control”), Cronbach’s alpha would be increased. Because of this, Item 49 was deleted before using this scale in subsequent analyses; the resulting Cronbach’s alpha for this subscale was increased to 0.67 . In addition, the item-to-total correlations for items in each subscale are presented in Table 5. Items on the TPB had low to moderate correlations with the total subscale scores. The resulting 49-item TPB Questionnaire was used in Phase 3 of the study.

After full consideration of the psychometric properties of the TPB Questionnaire subscale scores, it was decided to use the component scores (i.e., attitude towards behavior, subjective norms, and perceived behavioral control) in the following regression analyses, as these components demonstrated adequate internal consistency compared to the underlying beliefs 
regarding these TPB components (i.e., behavioral beliefs, normative beliefs, and control beliefs). Other studies using the TPB model have used a similar approach (e.g., Keats, Culos-Reed, Coumey, and McBride, 2007; Murnaghan et al., 2010); that is, theses studies have used the components of the TPB to examine the behavioral intentions of health behaviors.

\section{Aim 3}

\section{Data Management}

Prior to data analyses for Phase 3, all data were checked for issues with missing values, violations of normality and homogeneity, and possible outliers. In cases of missing data, if participants were missing items for one questionnaire, their responses for that questionnaire were excluded from data analyses. The sample sizes for all analyses are presented in the tables to provide information on how many cases were excluded due to missing data. Outliers were deleted if they were found to significantly impact the normality of the data. Furthermore, multicollinearity among study variables was evaluated (i.e., correlations, VIF and Tolerance values) and appropriate steps were taken if multicollinearity was a significant concern (e.g., variables will be combined or reduced).

The $B A S C$-2 provides a variety of validity scores, which range from acceptable, caution, and extreme caution. Participants whose scores indicated extreme (i.e., validity scores were caution and/or extreme caution) carelessness and inconsistency were excluded from analyses that used the BASC-2 scores. This excluded a total of 14 participants from the analyses.

Means and standard deviations of all study variables are presented in Table 6. Means and standard deviations of the BASC-2 standard scores are presented in Table 7 to provide additional descriptive information on the study sample. Bivariate correlations (i.e., Pearson) among all study variables are presented in Table 8. A close examination of the correlations revealed that 
age was significantly correlated with SES $(r=.14)$, geographic location $(r=-.44)$, parental behavior control ( $r=-.31)$, rebellious behavior $(r=.27)$, and reckless behavior $(r=.49)$. Age was subsequently controlled for in analyses where it was a significant correlate (as noted below).

Aim 3. The final aim was to investigate the degree to which the components of the TPB predict adolescents’ intentions to engage in fire-risk behaviors. A multiple regression analysis was conducted that included the three components of the TPB (i.e., attitude, subjective norm, and perceived behavioral control) entered simultaneously as predictors of behavioral intention to engage in fire-risk behaviors. Together, the combined TPB components significantly predicted youth's behavioral intentions to engage in fire-risk behaviors, $F(3,207)=42.84, p<.001$. This model accounted for 38.3\% amount of variance (Adj. $R^{2}=.37$ ). Further examination of individual predictors revealed that attitude towards behavior $(\beta=.49, p<.001)$ and subjective norms ( $\beta=.18, p=.005$ ) were significant predictors of youth's intention to engage in risky fire behaviors (see Table 9), suggesting that youth who held positive attitudes towards fire-risk behaviors and who believed significant others would approve of them engaging in fire-risk behaviors tended to have more intentions to engage in fire-risk behaviors.

Aim 3a. This aim sought to further understand the relation among the underlying beliefs of the TPB with the TPB components. To examine this aim, a series of bivariate correlations (i.e., Pearson) were calculated among the underlying beliefs (i.e., behavioral, normative, and control beliefs) and the components of the TPB (i.e., attitudes, subjective norms, and perceived behavioral control). As shown in Table 10, the underlying beliefs were significantly correlated with their respective TPB components and behavioral intentions. Of note, "having a lot of fun” and "getting in trouble with parents" were strongly correlated with attitudes towards behavior (i.e., engagement in fire-risk behaviors), indicating that adolescents' beliefs that they will have 
fun and will get in trouble with their parents may be related to their overall attitude towards the behavior. Parents and friends were strongly correlated with subjective norms, suggesting that parents and friends may play a large role in adolescents’ beliefs of who would approve (or disapprove) of them engaging in fire-risk behaviors. Finally, "having the right resources” was strongly correlated with perceived behavioral control, suggesting that access to the right resources may influence adolescents’ behavioral control (i.e., self-efficacy) to engage in fire-risk behaviors.

Aim $3 \boldsymbol{b}$. Finally, this aim evaluated the extent to which TPB components were able to predict adolescents' intentions to engage in fire-risk behaviors while controlling for various background variables. This aim was addressed through a series of hierarchical regression analyses. Due to the large number of control variables included in this study, five separate hierarchical regression models were conducted to test this aim.

The first hierarchical regression analysis examined the three TPB components as predictors of fire-risk behavioral intentions while controlling for age, SES, geographic location, and gender. Because age was significantly correlated with SES, it was entered into the first step of the model. Next, as hypothesized, SES, geographic location, and gender were entered into the second step of the model. The three TPB components were entered into the third step of the model. As shown in Table 11, the first step of the model was not significant, $F(1,200)=.03, p=$ .948. The second step of the model also was not significant, $F(4,197)=.770, p=.546$. However, the addition of the TPB components in Step 3 of the model resulted in a significant model, $F(7,194)=17.01, p<.001, R^{2}=.38$, Adj. $R^{2}=.36, R^{2}$ change $=.37$. The TPB components of attitude towards behavior and subjective norms were significant predictors of youth’s behavioral intentions to engage in fire-risk behaviors, suggesting that youth with more positive attitudes 
towards in fire-risk behaviors and youth with more perceived social pressure from important others tended to endorse more intentions to engage in fire-risk behaviors (see Table 11). Overall, these results indicated that the TPB components were able to account for a significant amount of the variance in adolescents' intention to engage in fire-risk behaviors, over and above the demographic variables of SES, geographic location (urban vs. rural), and gender

The second hierarchical regression analysis controlled for psychopathology variables (i.e., anxiety, sensation-seeking, hyperactivity, and attention problems) while examining the three ТPB components as predictors of behavioral intentions to engage in fire-risk behaviors. Results indicated that the first step of the model (psychopathology variables) accounted for a significant amount of variance in youth's behavioral intentions, $F(4,191)=5.90, p<.001, R^{2}=$ .11 , Adj. $R^{2}=.09$. Step 2 (i.e., inclusion of TPB components) of the model accounted for an additional $30 \%$ of the variance in behavioral intentions $\left(R^{2}\right.$ change $\left.=.30\right)$. Step 2 was significant, $F(7,188)=18.86, p<.001, R^{2}=.41$, Adj. $R^{2}=.39$. As shown in Table 12, sensation seeking, attitude towards behavior, and subjective norms were significant predictors of adolescents’ intention to engage in fire-risk behaviors. Based on these results, it appears that youth with higher sensation seeking scores, more positive attitudes towards fire-risk behaviors, and more significant others who would approve of engagement in fire-risk behaviors were likely to have more intentions to engage in fire-risk behaviors. In addition, these results suggest that the TPB components were able to account for a significant amount of the variance in youth's behavioral intentions over and above psychopathology variables, with the exception of sensation seeking. In the third model, Step 1 included fire and burn safety knowledge, while Step 2 included the three TPB components. Step 1 (knowledge scores as predictors) of the model was not significant, $F(1,207)=.25, p=.615$. However, the addition of the TPB components to the 
model resulted in a significant model, Step $2 F(4,204)=31.01, p<.001, R^{2}=.38$, Adj. $R^{2}=.37$. This step accounted for an additional $37.7 \%$ of the variance in behavioral intentions. Similar to previous results, attitude towards behavior and subjective norms were significant predictors of adolescents' intention to engage in fire-risk behaviors (see Table 13). Youth with more positive attitudes towards fire behaviors and who perceived more support from significant others were more likely to endorse intent to engage in fire-risk behaviors, after controlling for fire and burn safety knowledge.

The fourth hierarchical regression examined the TPB components as predictors of behavioral intentions while controlling for age and parental monitoring (i.e., parental solicitation, child self-disclosure, and parental behavioral control). Because age was significantly correlated with parental behavioral control, it was entered into Step 1 of the model. Step 2 included the parental monitoring variables. Step 3 included the TPB components. Step 1 was not significant, $F(1,171)=0.06, p=.812$. Results from the second step revealed a non-significant model, $F(4$, $168)=0.29, p=.884$. Results from Step 3 of the model were significant, $F(7,165)=13.20, p<$ $.001, R^{2}=.36$, Adj. $R^{2}=.33$ and explained an additional $35.2 \%$ of the variance in adolescents' intentions to engage in fire-risk behavior. Attitude towards behavior and subjective norms were again significant predictors of adolescents’ behavioral intentions (see Table 14), suggesting that adolescents who hold more positive attitudes towards fire-risk behaviors, as well as believe significant others would approve of them engaging in fire-risk behaviors, tended to rate more intentions to engage in fire-risk behaviors, over and above age and parental monitoring factors.

Finally, the fifth hierarchical regression analysis controlled for age, reckless behavior, and rebellious behavior while examining the TPB components as predictors of behavioral intentions. Age was entered into the first step of the model, as it was significantly correlated with 
both reckless and rebellious behavior. The second step included reckless and rebellious behavior, while the third step included the TPB components. Step 1 was not significant, $F(1,192)=.044, p$ $=.835$. The second step of the model was significant, $F(3,190)=9.16, p<.001, R^{2}=.13$, Adj. $R^{2}=.12$. In the second step, age and rebellious behavior were significant predictors of behavioral intentions. The addition of the TPB components in Step 3 resulted in a significant model, F(6, $187)=22.82, p<.001, R^{2}=.65$, Adj. $R^{2}=.40$ and accounted for an additional $29.6 \%\left(R^{2}\right.$ change $=.29$ ) of the variance in adolescents' intentions to engage in fire-risk behaviors. In this final step, age, rebellious behavior, attitude towards behavior, and subjective norms were significant predictors of behavioral intentions (see Table 15). These results indicated that older adolescents and adolescents who engaged in more rebellious behavior tended to report more intentions to engage in fire-risk behaviors. In addition, adolescents who had more positive attitudes towards fire-risk behaviors and who had more significant others who approved of them engaging in firerisk behaviors reported more behavioral intentions to engage in these behaviors. Taken together, the TPB components of Attitude towards Behavior and Subjective Norms were able to account for a significant amount of the variance in adolescents' behavioral intentions; however, age and rebellious behavior were also significant predictors of adolescents’ behavioral intentions to engage in fire-risk behaviors.

\section{Discussion}

Burn injuries are a serious concern for youth. In particular, adolescents tend to be at risk for sustaining burn injuries that are caused by thermal or flame sources (American Burn Association National Burn Repository, 2013; Peck, 2011). Recent estimates suggest that approximately 603,000 adolescents are treated for burn injuries in emergency departments each year in the United States (D’Souza, Nelson, \& McKenzie, 2009). Due to the serious 
consequences of burn injuries (i.e., hospitalization, painful medical treatments, rehabilitation, and permanent scarring), prevention programs are needed that address the specific developmental needs of adolescents. However, no such adolescent programs have been developed thus far. Not only is there a dire need for fire and burn prevention programs specifically tailored to adolescents, but these programs should be rooted in scientific findings. Theories of health behavior, such as Ajzen's Theory of Planned Behavior (TPB), can be used to help understand why adolescents may engage in behaviors that put them at risk for sustaining a burn injury. Briefly, Ajzen’s TPB (1991; 2005) suggests that individuals will intend to perform a behavior if they have a positive attitude about the behavior (i.e., attitude towards the behavior), if they have important others who approve of them engaging in the behavior (i.e., subjective norms), and if they believe that their behavior is under their control (i.e., perceived behavioral control). Previous research using the TPB has demonstrated the utility of this model in predicting variance in youth's behavioral intentions to engage in a variety of health behaviors (e.g., soda consumption, physical exercise), with values ranging from 33.7\% to 64\% (e.g., Kassem, Lee, Modeste, \& Johnston, 2003; Keats, Culos-Reed, Courneya, \& McBride, 2007). In addition to examining the application of the TPB to adolescents' behavioral intentions to engage in fire-risk behaviors, this study also examined the ability of the components of the TPB to predict adolescents' intention over and above a variety of control or background variables, all of which are relevant and/or have been shown to be related to burn injury outcomes (e.g., Peck, 2011; Patterson et al., 2003).

The overall objective of the present study was to test the TPB in predicting fire-burn risk behaviors in adolescents. Three study phases were conducted to create study measures specific to fire-risk behaviors, pilot those measures to examine the initial psychometric properties, and use 
the measures with a large sample of adolescents to address the overall objective. In the first phase, results from the focus group phase (i.e., frequencies of responses to a semi-structured interview) were used to create the TPB Questionnaire and the Fire and Burn Injury Safety Questionnaire. Results from the second phase (i.e., pilot administration of measures) demonstrated that the created measures had adequate psychometric properties. Consequently, these measures were used in the third phase of the project to examine the TPB in predicting youth fire-risk behaviors.

As hypothesized, the TPB components were significant predictors of adolescents’ behavioral intentions to engage in risky fire behaviors and accounted for $38.3 \%$ of the variance in this outcome. Previous studies using the TPB to predict various adolescent health behaviors have found similar results, with the amount of variance ranging from $33.7 \%$ in one study (Keats, Culos-Reed, Courneya, \& McBride, 2007) to 64\% in another study (Kassem, Lee, Modeste, \& Johnston, 2003). Consistent with previous literature, the TPB components of subjective norms and attitude towards behavior emerged as significant predictors of this relation. Developmentally, adolescence is a time where social pressure (i.e., subjective norms) and attitude formation may play a role in determining adolescent behavior - particularly health risk behavior. Indeed, Murnaghan and colleagues (2010) found that subjective norms were a significant predictor of adolescents' intention to consume fruits and vegetables, engage in physical activity, and be smoke-free. Others studies that did not use the TPB have found similar results (e.g., Simons-Morton, Chen, Abroms, \& Haynie, 2004), suggesting that social influences are important to consider when examining health behaviors. In addition, attitudes towards behaviors have been found to be significant predictors of a variety of health behaviors during adolescence (e.g., Keats, Culos-Reed, Courneya, \& McBride, 2007). 
Surprisingly, perceived behavioral control (i.e., individuals’ control of their behaviors around fire-risk behaviors) was not a significant predictor of adolescents' intention to engage in fire-risk behaviors. Previous studies using the TPB (e.g., Murnaghan et al., 2010) demonstrated that this variable was a significant predictor of adolescents' behavioral intentions to engage in various health behaviors. It could be that fire-risk behaviors occur at a relatively low frequency (e.g., individuals may have campfires only occasionally during the year or use fireworks only at holidays) and thus adolescents do not feel competent (or confident) in their skills to control these behaviors. It might also be that adolescents are engaging in fire-risk behaviors with peers and therefore do not feel solely responsible for their fire-risk behaviors. Finally, it could be that adolescents perceive fire and burn injuries as accidents and as a result, view burn-fire risk as something that is externally controlled (e.g., bad luck). However, in this study, adolescents rated higher levels of perceived behavioral control $(M=4.28, S D=1.42)$, suggesting that they perceived to have control around fire-risk behaviors. Therefore, despite feeling in control around fire-risk behaviors, having control was not related to youth's behavioral intentions to engage in fire-risk behaviors. Nonetheless, further research is needed to clarify the role of perceived behavioral control in fire-risk behaviors, as this information could inform the development of prevention programs. For example, if perceived behavioral control was found to be a significant predictor of behavioral intentions (either high or low perceived behavioral control), a skillsbased approach (e.g., how to properly start a campfire) could be used to teach youth how to be safe (i.e., have more control) around situations that pose risks for fire and/or burn injuries (e.g., campfires).

To better understand the relation among the TPB components and behavioral intentions, correlations among the TPB components and the underlying beliefs of these components (i.e., 
behavioral beliefs, normative beliefs, and control beliefs) and behavioral intentions were calculated. Results indicated that attitudes such as having fun were strongly associated with behavioral intentions. In addition, perceived approval of parents and peers were significantly correlated with adolescents' behavioral intentions, in that having parents and peers who approve of engaging in these behaviors was correlated with increased likelihood of engaging in fire-risk behaviors. Finally, having friends who want to engage in fire-risk behaviors and having the necessary resources was associated with adolescents’ behavioral intentions. These correlations provide valuable insight into adolescents’ behavioral intentions to engage in fire-risk behaviors, suggesting that these intentions may be amenable to change through prevention programs.

Various background predictors were included in this study to examine their relation with youth’s intentions to engage in fire-risk behaviors. Demographics variables, including SES, geographic location (urban vs. rural), and gender were not significant predictors of adolescents’ behavioral intentions to engage in fire-risk behaviors, despite previous research suggesting that these variables may be related to adolescents’ risk for sustaining burn injuries (e.g., Peck, 2011). Given that this study only examined adolescents’ behavioral intentions to engage in fire-risk behavior and did not measure actual behavior, it could be that these demographic variables may play a role in explaining actual engagement in fire-risk behaviors and burn injuries, rather than intentions.

Similarly, anxiety, hyperactivity, and attention problems were not significant predictors of behavioral intentions to engage in fire-risk behaviors. As previously discussed, it could be that these variables are important when explaining actual engagement in fire-risk behaviors, and do not play a role in determining adolescents' behavioral intentions to engage in fire-risk behaviors. Sensation seeking was the only psychopathology variable that was associated with adolescents’ 
behavioral intentions. Although this relation was not as predicted (i.e., it was hypothesized that the TPB components would predict adolescents' intentions over and above sensation seeking), it is logical to think that participants who rate high in sensation-seeking (i.e., the need for sensory stimulation and engagement in risk-taking to achieve that stimulation) may also endorse more intentions to engage in fire behaviors, which are inherently risky and may provide a sense of "thrill” or challenge. Research suggests that sensation seeking typically increases during adolescence (e.g., Spear, 2000), which may help explain why sensation seeking was a significant predictor of behavioral intentions in the current sample of adolescents. Furthermore, previous research has suggested a link between sensation seeking and engagement in other risky behaviors, such as drug use (e.g., Romer \& Hennessy, 2007).

Next, fire and burn safety knowledge was not a significant predictor of adolescents’ intention to engage in fire-risk behavior. Despite limited research suggesting an association between knowledge and burn injuries, it was thought that a lack of knowledge might put adolescents at risk for burn injuries. For example, an adolescent may not know how to properly start a fire, which in turn could lead to him/her starting a fire in a dangerous manner (e.g., with gasoline or another accelerant). However, it might be that even with having fire and burn safety knowledge, this does not necessarily change adolescents’ intention to engage in fire-risk behaviors. Rather, having knowledge may influence precautions adolescents may take (e.g., not using gasoline with fires) while engaging in fire behaviors. Another possible explanation for the lack of findings was the created measure designed to assess fire and burn safety knowledge in this study. The internal consistency of this measure was somewhat limited and this may have influenced the results. It could be that the items included in this measure varied in difficulty and content (e.g., some pertained to prevention of fire/burn, while others addressed responding 
initially to a fire/burn situation), thus resulting in low internal reliability among the items. It might also be that items were assessing various factors of fire and burn safety knowledge, and thus items may be more reliable when separated into appropriate subscales. Because of these limitations with the Fire and Burn Injury Safety Questionnaire, caution should be used when interpreting results using this measure. However, this was a first step in creating a reliable measure of adolescent fire and burn safety knowledge, as no such measures currently exist in the literature. Future studies should continue to develop and refine the Fire and Burn Injury Safety Questionnaire (e.g., conduct a factor analysis, examine validity) to fully understand the relation between this type of knowledge and adolescents' intention to engage in fire-risk behaviors.

Parental monitoring (i.e., parental solicitation of child behavior, child self-disclosure, and parental behavior control) was not significantly predictive of youth behavioral intentions to engage in fire-burn risk behaviors. As suggested by the subjective norms, it could be that parents approve of (and may even engage in) fire-risk behaviors endorsed by the teens; thus, there may not be specific rules about these behaviors and/or parents may not provide appropriate monitoring. This is consistent with the burn literature, as studies suggest that parental monitoring at the time of burn injuries is often questionable or lacking (e.g., Carrigan, Heimback, \& Marvin, 1988; Morrongiello, Ondejko, \& Littlejohn, 2004b). Based on these results, prevention programs that seek to increase parental monitoring may not be as effective as prevention programs that address other individual variables (described below).

Finally, rebellious behavior was found to be a significant predictor of adolescents’ behavioral intentions to engage in fire-risk behaviors. As previously discussed, adolescence is a time characterized by increased risk-taking behavior (Reyna \& Farley, 2006). It is likely that adolescents who tend to engage in rebellious behaviors (e.g., drinking, smoking) are also more 
likely to engage in fire behaviors, a similar risky behavior. As such, fire and burn prevention programs may need to specifically target youth who score high on measures of rebellious behavior, as these youth may be more likely to engage in fire-risk behaviors.

As hypothesized, the TPB components were able to account for more variance in adolescents' intention to engage in fire-burn risk behavioral intentions over and above a variety of factors, with the exception of the background variables of sensation seeking and rebellious behavior. Regardless of the background variables included in the model, the TPB components of attitude towards the behavior and subjective norms were significant predictors of adolescents’ behavioral intentions to engage in fire-risk behaviors. Across all models that controlled for various background variables, results suggested that youth who held more positive attitudes towards fire-risk behaviors and youth who perceived more important others would approve of them engaging in fire-risk behaviors tended to endorse more intentions to engage in fire-risk behaviors. These results are quite meaningful, and can greatly inform the development of prevention programs. For example, prevention programs could target adolescents' attitudes as well as address methods to resist social pressure to engage in fire-risk behaviors.

Previous research has examined prevention programs that were informed by the TPB constructs. A systematic review of interventions that targeted TPB constructs found that out of 13 studies, half of the studies reported changes in behavioral intentions, while two thirds of the studies reported changes in actual behavior after the completion of TPB interventions (Hardeman et al., 2002). The authors of this review discussed that TPB interventions involved both cognitive and behavioral strategies, despite the fact that TPB is more relevant to cognitive theory (Hardeman et al., 2002). The TPB interventions that did focus on cognitive strategies tended to provide knowledge and utilize persuasion techniques to elicit change in behaviors and intention 
(Hardeman et al., 2002). As another example, Milton and Mullan (2012) developed a TPB intervention to target young adults’ food safety procedures. To address attitudes toward the behavior, the intervention sought to change young adults' affective and cognitive attitudes, as well as their risk perceptions towards food safety by providing knowledge about food safety and consequences associated with poor food safety (i.e., food-borne illnesses). The TPB intervention also sought to change normative beliefs (i.e., subjective norms) by providing information on who would approve/disapprove of food safety. Finally, the TPB intervention targeted perceived behavioral control by motivational techniques to improve self-efficacy and identifying and addressing barriers to engaging in positive food safety. Participants who completed the TPB intervention (compared to control groups) were found to have increased perceived behavioral control over their food safety practices (Milton \& Mullan, 2012). In addition, participants in the TPB intervention were observed to engage in food safety behaviors four weeks post-intervention (Milton \& Mullan, 2012).

Currently, burn prevention programs for other age groups are quite limited. These programs typically target fire and burn prevention knowledge (e.g., Grant, Turney, Bartlett, Winbon, \& Peterson, 1992), rather than focus on other constructs relevant to TPB. Because of the limited research in this area, results from this study provide a large step towards developing a scientifically based fire and burn prevention program for teenagers. Prevention programs that target other health behaviors in adolescents (e.g., alcohol use) do a much better job of addressing a variety of factors in addition to knowledge, such as targeting social influences, attitudes, and norms as well as training in social refusal skills (e.g., Kulis, Nieri, Yabiku, Stromwall, \& Marsiglia, 2007). It is not surprising then that results from the current study suggest that including components such as attitudes toward fire-burn risk behavior and addressing perceived 
social pressure (as some studies do) might enhance the effectiveness of fire and burn prevention for adolescents. In particular, targeting these factors may lead to a decrease in adolescent intentions to engage in fire-risk behaviors, which in turn may reduce the frequency of fire and burn related injuries in this population.

Another key implication of the study findings is the potential utility of the newly created questionnaires in routine patient care. For instance, the Fire and Burn Injury Safety Questionnaire and the TPB Questionnaire may be used with children in primary care clinics to assess their knowledge and beliefs about fire behaviors. Children may complete the Fire and Burn Injury Safety Questionnaire while waiting for their appointments and can go over the results with their doctors during their appointments to review safety strategies. Indeed, most primary care clinics review various safety strategies with patients and their parents. These questionnaires could be used as part of the review of safety strategies and provide more specific information that is tailored to the individual patients' needs.

This study was not without limitations. First, the focus groups were conducted with youth from a rural location; thus, the information gained from these focus groups, which was used to design study measures, may not have generalized to youth in more urban areas. In addition, the focus groups were small and some "groups” only consisted of one participant. Only including one participant during the semi-structured interview may have limited the variety of responses, as participants in groups were able to have more discussion about the questions after listening to contributions from their peers. Participants in groups also may have felt more comfortable and supported in discussing their thoughts than when meeting one-on-one with the principal investigator. In addition, only ten participants were included in the focus groups; this study may 
have benefited from increasing the sample size, in its first phase, to gather more information on adolescents’ beliefs and thoughts about engaging in fire-risk behaviors.

As discussed previously, the Fire and Burn Injury Safety Questionnaire had somewhat limited internal consistency, which may have limited the ability of this measure to predict adolescents’ intentions to engage in fire-risk behaviors. The reckless behavior subscale also had low internal consistency. Because of this, caution should be used when interpreting results using these measures, as low internal reliabilities suggest that the items may not be closely related.

In addition, only one researcher coded responses for the Fire and Burn Injury Safety Questionnaire. Future studies will benefit from including a more comprehensive approach to coding this questionnaire and examining its reliability. According to the literature (e.g., Burla et al., 2008; Lombard, Snyder-Duch, \& Bracken, 2002), this approach would involve having two researchers who are trained in the coding of the questionnaire. These two coders would then code $25-30 \%$ of the questionnaires to reach an appropriate standard of reliability (kappa $=.70$ or greater). Once that standard is reached, the coders would be randomly assigned the remaining questionnaires, while conducting random samples of double-coding throughout the entire pool of questionnaires to ensure that no drift occurred.

Another limitation is that the parental monitoring measure was not specific to monitoring of adolescent fire-risk behavior. It may be that parental monitoring varies when the behavior to be monitored is a fire-risk behavior. Also, only adolescents completed study measures, which were all self-report measures of behaviors; the inclusion of parent and/or objective ratings of behaviors may have provided additional information or perspectives on participants' engagement in fire-risk behaviors. As only adolescents completed the self-report measures, shared-informant and shared-method variance may have increased the likelihood of finding significant results. 
Other limitations may be due to participant characteristics. Due to the sensitive nature of some of the questionnaires (e.g., TPB Questionnaire and evaluation of fire-risk behaviors, Adolescent Risk-Taking Questionnaire), participants may have responded in socially desirable ways. In addition, participants were recruited mostly from health classes and thus may have been previously exposed to injury prevention topics. Participants completed questionnaires while their teachers were in the room (and in some instances while the teachers were conducting a lesson), which may have distracted participants from fully attending to the questions. Also, recruitment rates for phases of the study were quite low, with the exception of the Morgantown High School sample in Phase 2. This may have impacted the results, as youth who did not participate may be different from youth who did participate. It is possible that upon hearing that this study was about fire risk behaviors (during the consent procedures), participants were hesitant to participate in a study that asked them questions about a risky behavior. Furthermore, the cross-sectional design of the study prevents any causal inferences. Finally, this study did not measure actual engagement in fire-risk behavior and so it is unclear if behavioral intentions to engage in fire-risk behaviors are a significant predictor of adolescents’ engagement in these behaviors.

As this was one of the first studies to use a theoretical basis to examine factors associated with adolescents' intention to engage in fire-risk behaviors, future research should continue to investigate attitudes, subjective norms, and perceived behavioral control, as well as other variables that may be associated with adolescents’ fire-risk behavioral intentions, such as perceived threat of burn injuries, cultural practices, or affect. In addition, examination of fire-risk behaviors using other theories of health behaviors (e.g., Health Belief Model) may provide additional insight into fire-risk behaviors. It is imperative that future research continues to evaluate fire-risk behaviors during adolescence, as a greater understanding of this behavior can 
be used to inform the development of effective and targeted fire and burn prevention programs for teenagers. 


\section{References}

Abeyasundara, S.L., Rajan, V., Lam, L., Harvey, J.G., \& Holland, A.J.A. (2011). The changing pattern of pediatric burns. Journal of Burn Care \& Research, 32, 178-184. doi:

10.1097/BCR.0b013e31820aada8

Ali, M., Haidar, N., Ali, M.M., \& Maryam, A. (2010). Determinants of seat belt use among drivers in Sabzevar, Iran: A comparison of theory of planned behavior and health belief model. Traffic Injury Prevention, 12, 104-109. doi: 10.1080/15389588.2010.535227

Ajzen, I. (2005). From intentions to actions. In I. Ajzen (Ed.), Attitudes, personality and behavior-2 ${ }^{\text {nd }}$ Edition (pp. 99-116). Berkshire, England and New York, New York: Open University Press.

Ajzen, I. (2005). Explaining intentions and behavior. In I. Ajzen (Ed.), Attitudes, personality and behavior-2 ${ }^{\text {nd }}$ Edition (pp. 117-141). Berkshire, England and New York, New York: Open University Press.

Ajzen, I. (1991). The theory of planned behavior. Organizational Behavior and Human Decision Processes, 50, 179-211. doi: 10.1016/0749-5978(91)90020-T

Ajzen, I. \& Driver, B.L. (1992). Application of the theory of planned behavior to leisure choice. Journal of Leisure Research, 24, 207-224.

American Burn Association. (2013, March). Retrieved from http://www.ameriburn.org/.

American Burn Association. (2013, March). National Burn Repository. Retrieved from http://www.ameriburn.org/.

American Psychiatric Association. (2000) Diagnostic and statistical manual of mental disorders; text revision. $4^{\text {th }}$ ed. Washington, DC: American Psychiatric Association. 
Armitage, C.J. \& Conner, M. (2001). Efficacy of the theory of planned behavior: a meta-analytic review. British Journal of Social Psychology, 40, 417-499. doi: 10.1348/014466601164939

Bachanas, P.J., Morris, M.K.., Lewis-Gess, J.K., Sarett-Cuasay, E.J., Flores, A.I., Sirl, K.S., \& Sawyer, M.K. (2002). Psychological adjustment, substance use, HIV knowledge, and risky sexual behavior in at-risk minority females: Developmental differences during adolescence. Journal of Pediatric Psychology, 27, 373-384. doi: 10.1093/jpepsy/27.4.373

Badger, K., Anderson, L., \& Kagan, R.J. (2008). Attention deficit-hyperactivity disorder in children with burn injuries. Journal of Burn Care \& Research, 29(5), 724-729. doi: 10.1097/BCR.0b013e31818480e1

Brehaut, J.C., Miller, A., Raina, P., \& McGrail, K.M. (2003). Childhood behavior disorders and injuries among children and youth: A population-based study. Pediatrics, 111(2), 262270. doi: 10.1542/peds.111.2.262

Burla, L., Knierim, B., Barth, J., Liewald, K., Duetz, M., \& Abel, T. (2008). From text to codings: Intercoder reliability assessment in qualitative content analysis. Nursing Research, 57(2), 113-117.

Carrigan, L., Heimbach, D.M., \& Marvin, J.A. (1988). Risk management in children with burn injuries. Journal of Burn Care \& Rehabilitation, 9(1), 75-78.

Centers for Disease Control and Prevention. (2010). National Center for Injury Prevention and Control: Fatality statistics. Retrieved from http://www.cdc.gov/injury/wisqars/index.html. Centers for Disease Control and Prevention. (2011). STD trends in the United States. Retrieved from http://www.cdc.gov/std/stats11/default.htm. 
Centers for Disease Control and Prevention. (2012, August). Retrieved from http://www.cdc.gov/safechild/Burns/index.html.

Conner, M. \& Sparks, P. (2005). Theory of planned behavior and health behavior. In M. Conner \& P. Newman (Eds.), Predicting health behavior-2 ${ }^{\text {nd }}$ Edition (pp. 170-222). Berkshire, England: Open University Press.

D’Souza, A.L., Nelson, N.G., \& McKenzie, L.B. (2009). Pediatric burn injuries treated in US emergency departments between 1990 and 2006. Pediatrics, 124(5), 1424-1430. doi: 10.1542/peds.2008-2802

Fagenholz, P.J., Sheridan, R.I., Harris, N.S., Pelletier, A.J., Camargo Jr, C.A. (2007). National study of emergency department visits for burn injuries, 1993 to 2004. Journal of Burn Care \& Research, 28, 681-690. doi: 10.1097/BCR.0B013E318148C9AC

Francis, J.J., Eccles, M.P., Johnston, M., Walker, A., Grimshaw, J., Foy, R., Kaner, E.F.S., Smith, L., \& Bonetti, D. (2004). Constructing questionnaires based on the theory of planned behavior: A manual for health services researchers.

Gerend, M.A. \& Shepherd, J.E. (2012). Predicting human papillomavirus vaccine uptake in young adult women: Comparing the Health Belief Model and Theory of Planned Behavior. Annals of Behavioral Medicine, 44, 171-180. doi: 10.1007/s12160-012-9366-5

Godin, G \& Kok, G. (1996). The theory of planned behavior: a review of its applications to health-related behaviors. American Journal of Health Promotion, 11(2), 87-98. doi: 10.4278/0890-1171-11.2.87

Grant, E., Turney, E., Bartlett, M., Winbon, C., \& Peterson, H.D. (1992). Evaluation of a burn prevention program in a public school system. Journal of Burn Care \& Rehabilitation, 13, 703-7. 
Gullone, E., Moore, S., Moss, S., \& Boyd, C. (2000). The Adolescent Risk-Taking Questionnaire: Development and Psychometric Evaluation. Journal of Adolescent Research, 15, 231-250. doi: 10.1177/0743558400152003

Hardeman, W., Johnston, M., Johnston, D.W., Bonetti, D., Wareham, N.J., \& Kinmonth, A.L. (2002). Application of the theory of planned behavior in behavior change interventions: A systematic review. Psychology and Health, 17(2), 123-158.

Hollingshead, A. B. (1975). Four factor index of social status. Unpublished manuscript. Yale University, New Haven, CT.

Igra, V. \& Irwin, C.E. (1996). Theories of adolescent risk-taking behavior. In R.J. Diclemente, W.B. Hansen, \& L.E. Ponton (Eds.), Handbook of Adolescent Health Risk Behavior (pp. 35-53). New York, NY: Plenum Press.

Istre, G.R., McCoy, M.A., Osborn, L., Barnard, J.J., \& Bolton, A. (2001). Deaths and injuries from house fires. New England Journal of Medicine, 344(25), 1911-1916. doi: 10.1056/NEJM200106213442506

Kulis, S., Nieri, T., Yabiku, S., Stromwall, L.K., \& Marsiglia, F.F. (2007). Promoting reduced and discontinued substance use among adolescent substance users: Effectiveness of a universal prevention program. Prevention Science, 8, 35-49.

Lajunen, T. \& Rasanen, M. (2004). Can social psychological models be used to promote bicycle helmet use among teenagers? A comparison of the Health Belief Model, Theory of Planned Behavior and Locus of Control. Journal of Safety Research, 35, 115-123. doi: 10.1016/j.jsr.2003.09.020 
Lombard, M., Snyder-Duch, J., \& Bracken, C.C. (2002). Content analysis in mass communication assessment and reporting of intercoder reliability. Human Communication Research, 28(4), 587-604.

Kassem, N.O., \& Lee, J.W. (2004). Understanding soft drink consumption among male adolescents using the theory of planned behavior. Journal of Behavioral Medicine, 27(3), 273-296. doi: 0160-7715/04/0600-0273/0

Kassem, N.O., Lee, J.W., Modeste, N.N., \& Johnston, P.K. (2003). Understanding soft drink consumption among female adolescents using the theory of planned behavior. Health Education Research, 18(3), 278-291. doi: 10.1093/her/cyf017

Keats, M.R., Culos-Reed, S.N., Courneya, K.S., \& McBride, M. (2007). Understanding physical activity in adolescent cancer survivors: An application of the theory of planed behavior. Psycho-Oncology, 16, 448-457. doi: 10.1002/pon.1075

Kerr, M. \& Stattin, H. (2000). What parents know, how they know it, and several forms of adolescent adjustment: Further support for a reinterpretation of monitoring. Developmental Psychology, 36(3), 366-380.

Joseph, K.E., Adams, C. D., Goldfarb, I.W., \& Slater, H. (2002). Parental correlates of unintentional burn injuries in infancy and early childhood. Burns, 28(5), 455-463. doi: 10.1016/S0305-4179(02)00035-9

Mangus, R.S., Bergman, D., Zieger, M., \& Coleman, J.J. (2004). Burn injuries in children with attention-deficit/hyperactivity disorder. Burns, 30, 148-150. doi:10.1016/j.burns.2003.09.020 
Milton, A.C. \& Mullan, B.A. (2012). An application of the theory of planned behavior-A randomized controlled food safety pilot intervention for young adults. Health Psychology, 31(2), 250-259.

Morrongiello, B.A., Ondejko, L., \& Littlejohn, A. (2004a). Understanding toddlers’ in-home injuries: I. Context, correlates, and determinants. Journal of Pediatric Psychology, 29(6), 415-431. doi: 10.1093/jpepsy/jsh046

Morrongiello, B.A., Ondejko, L., \& Littlejohn, A. (2004b). Understanding toddlers’ in-home injuries: II. Examining parental strategies, and their efficacy, for managing child injury risk. Journal of Pediatric Psychology, 29(6), 433-446. doi: 10.1093/jpepsy/jsh047

Murnaghan, D.A., Blanchard, C.M., Rodgers, W.M., LaRosa, J.N., MacQuarrie, C.R., MacLellan, D.L., \& Gray, B.J. (2010). Predictors of physical activity, healthy eating and being smoke-free in teens: A theory of planned behavior approach. Psychology and Health, 25(8), 925-941. doi: 10.1080/08870440902866894

O’Callaghan, F.V. \& Nausbaum, S. (2006). Predicting bicycle helmet wearing intentions and behavior among adolescents. Journal of Safety Research, 37, 425-431. doi: 10.1016/j.jsr.2006.08.001

Patil, S.B., Khare, N.A., Jalswal, S., Jain, A., Chitranshi, A., \& Math, M. (2010). Changing patterns in electrical burn injuries in a developing country: Should prevention programs focus on the rural population. Journal of Burn Care \& Research, 31, 931-934. doi: 10.1097/BCR.0b013e3181f93924

Patterson, D.R., Finch, C.P., Wiechman, S.A., Bonsack, R., Gibran, N., \& Heimbach, D. (2003). Premorbid mental health status of adult burn patients: Comparison with a normative sample. Journal of Burn Care \& Research, 24, 347-350. 
Parker, D., Manstead, A.S.R., Stradling, S.G., Reason, J.T., \& Baxter, J.S. (1992). Intention to commit driving violations: An application of the theory of planned behavior. Journal of Applied Psychology, 77(1), 94-101. doi: 12361651

Peck, M.D. (2011). Epidemiology of burns throughout the world. Part I: Distribution and risk factors. Burns, 37, 1087-1100. doi: 10.1016/j.burns.2011.06.005

Piazza-Waggoner, C., Dotson, C., Adams, C.D., Joseph, K., Goldfarb, I.W., \& Slater, H. (2005). Preinjury behavioral and emotional problems among pediatric burn patients. Journal of Burn Care \& Rehabilitation, 26, 371-378.

Reyna, V.F. \& Farley, F. (2006). Risk and rationality in adolescent decision making: Implications for theory, practice, and public policy. Psychological Science in the Public Interest, 7, 1-44. doi: 10.1111/j.1529-1006.2006.00026.x

Reynolds, C.R. \& Kamphaus, RW. (2006). BASC-2: Behavior assessment for children, second edition manual. Upper Saddle River, NJ: Pearson Education, Inc.

Rhoades, D.R., Kridli, S.A.-O., \& Penpase, B. (2011). Understanding overweight and adolescents’ beliefs using the theory of planned behavior. International Journal of Nursing Practice, 17, 562-570. doi: 10.1111/j.1440-172X.2011.01971.x

Romer, D. \& Hennessy, M. (2007). A biosocial-affect model of adolescent sensation seeking: The role of affect evaluation and peer-group influence in adolescent drug use. Prevention Science, 8, 89-101.

Schwebel, D.C. \& Gaines, J. (2007). Pediatric unintentional injury: Behavioral risk factors and implications for prevention. Journal of Developmental \& Behavioral Pediatrics, 28, 245254. doi: 10.1097/01.DBP.0000268561.80204.2a 
Shields, B.J., Comstock, R.D., Fernandex, S.A., Xiang, H., \& Smith, G.A. (2007). Healthcare resource utilization and epidemiology of pediatric burn-associated hospitalizations, United States, 2000. Journal of Burn Care \& Research, 28, 811.826. doi: 10.1097/BCR.0b013e3181599b51

Simons-Morton, B., Chen, R., Abroms, L., \& Haynie, D.L. (2004). Latent growth curve analyses of peer and parent influences on smoking progression among early adolescents. Health Psychology, 23(6), 612-623.

Sleet, D.A., Trifiletti, L.B., Gielan, A.C., \& Simons-Morton, B. (2006). Individual-level behavior change models. In A.C. Gielan, D.A. Sleet, \& DiClemente (Eds.), Injury and violence prevention: behavioral science theories, methods, and applications (pp. 19-40). San Francisco, CA: Jossey Bass.

Smetana, J. G., \& Daddis, C. (2002). Domain-specific antecedents of parental psychological control and monitoring: The role of parenting beliefs and practices. Child Development, 73, 563-580.

Smetana, J.G., Metzger, A., Gettman, D.C., \& Campione-Barr, N. (2006). Disclosure and secrecy in adolescent-parent relationships. Child Development, 77(1), 201-217.

Spear, L.P. (2000). The adolescent brain and age-related behavioral manifestations. Neuroscince and Biobehavioral Reviews, 24, 417-463.

Stattin, H. \& Kerr, M. (2000). Parental monitoring: A re-interpretation. Child Development, 71, 1072-1085.

Thomas, C.R., Ayoub, M., Rosenberg, L., Robert, R.S., \& Meyer, W.J. (2004). Attention deficit hyperactivity disorder \& pediatric burn injury: a preliminary retrospective study. Burns, 30, 221-223. doi: 10.1016/j.burns.2003.10.013 
Tremblay, G.C. \& Peterson, L. (1999). Prevention of childhood injury: Clinical and public policy challenges. Clinical Psychology Review, 19(4), 415-434. doi: 10.1016/S02727358(98)00088-9

U.S. Census Bureau. (2013). Urban and rural classification. Retrieved from http://www.census.gov/geo/reference/urban-rural.html. 
Table 1

Descriptive Statistics for Phase 2 Demographic Variables

\begin{tabular}{|c|c|}
\hline & $n(\%)$ \\
\hline \multicolumn{2}{|l|}{ Child gender } \\
\hline Male & $40(47.6)$ \\
\hline Female & $44(52.4)$ \\
\hline \multicolumn{2}{|l|}{ Child race/ethnicity } \\
\hline Caucasian & $62(73.8)$ \\
\hline African American & $10(11.9)$ \\
\hline Asian American & $3(3.6)$ \\
\hline Bi-racial & $5(6.0)$ \\
\hline Other & $4(4.8)$ \\
\hline \multicolumn{2}{|l|}{ Grade in school } \\
\hline Ninth & $13(15.5)$ \\
\hline Tenth & $40(47.6)$ \\
\hline Twelfth & $31(36.9)$ \\
\hline \multicolumn{2}{|l|}{ Grades (academic performance) } \\
\hline Mostly A’s & $26(31.0)$ \\
\hline A's and B's & $31(36.9)$ \\
\hline Mostly B’s & $10(11.9)$ \\
\hline B's and C's & $11(13.1)$ \\
\hline C's and D's & $5(6.0)$ \\
\hline \multicolumn{2}{|l|}{ Father education level } \\
\hline High school diploma & $10(11.9)$ \\
\hline Some college or specialized vocational training & $12(14.3)$ \\
\hline Bachelor's degree & $25(29.8)$ \\
\hline Master's degree, doctoral degree & $24(28.6)$ \\
\hline \multicolumn{2}{|l|}{ Mother education level } \\
\hline High school diploma & $9(10.7)$ \\
\hline Some college or specialized vocational training & $12(14.3)$ \\
\hline Bachelor’s degree & $32(38.1)$ \\
\hline Master's degree, doctoral degree & $17(20.2)$ \\
\hline \multicolumn{2}{|l|}{ Family status } \\
\hline Intact, both biological parents & $47(56.0)$ \\
\hline Blended (e.g., step-parent) & $17(20.2)$ \\
\hline Single parent & $19(22.6)$ \\
\hline
\end{tabular}




\begin{tabular}{lc}
\hline Ever sustain burn injury? & $63(75.0)$ \\
Yes & $21(25.0)$ \\
No & \\
& \\
Ever hospitalized for burn injury? & $5(6.0)$ \\
Yes & $79(94.0)$ \\
No & \\
\hline Note. All values presented as Frequency $(\%)$.
\end{tabular}


Table 2

Descriptive Statistics for Phase 3 Demographic Variables

\begin{tabular}{|c|c|}
\hline & $n(\%)$ \\
\hline \multicolumn{2}{|l|}{ Child gender } \\
\hline Male & $66(29.7)$ \\
\hline Female & $154(69.4)$ \\
\hline \multicolumn{2}{|l|}{ Child race/ethnicity } \\
\hline Caucasian & $185(83.3)$ \\
\hline African American & $9(4.1)$ \\
\hline Bi-racial & $13(5.9)$ \\
\hline Asian American & $6(2.7)$ \\
\hline American Indian/Alaskan Native & $1(0.5)$ \\
\hline Other & $2(0.9)$ \\
\hline \multicolumn{2}{|l|}{ Grade in school } \\
\hline Ninth & $137(61.7)$ \\
\hline Tenth & $46(20.7)$ \\
\hline Eleventh & $25(11.3)$ \\
\hline Twelfth & $10(4.5)$ \\
\hline \multicolumn{2}{|l|}{ Grades (academic performance) } \\
\hline Mostly A’s & $83(37.6)$ \\
\hline A's and B's & $88(39.8)$ \\
\hline Mostly B’s & $10(4.5)$ \\
\hline B's and C's & $30(13.5)$ \\
\hline Mostly C's & $3(1.4)$ \\
\hline C's and D's & $5(2.3)$ \\
\hline D's and F's & $2(0.9)$ \\
\hline \multicolumn{2}{|l|}{ Father education level } \\
\hline High school diploma & $67(31.0)$ \\
\hline Some college or specialized vocational training & $44(20.4)$ \\
\hline Bachelor’s degree & 58 (26.9) \\
\hline Master's degree, doctoral degree & $41(19.0)$ \\
\hline \multicolumn{2}{|l|}{ Mother education level } \\
\hline High school diploma & $38(17.4)$ \\
\hline Some college or specialized vocational training & $62(28.4)$ \\
\hline Bachelor's degree & $59(27.1)$ \\
\hline Master’s degree, doctoral degree & $49(22.5)$ \\
\hline
\end{tabular}




\begin{tabular}{lc}
\hline Family status & $134(60.6)$ \\
Intact, both biological parents & $43(19.5)$ \\
Blended (e.g., step-parent) & $44(19.9)$ \\
Single parent & \\
Ever sustain burn injury? & $177(80.1)$ \\
Yes & $44(19.9)$ \\
No & \\
Ever hospitalized for burn injury? & $18(8.1)$ \\
Yes & $203(91.4)$ \\
No & \\
Note. All values presented as Frequency (\%). &
\end{tabular}


Table 3

Frequency of Responses Elicited from Focus Group Discussions

TPB Items
Fire-Risk Behaviors ("What kind of activities do you engage

in that involve fire?”)

Using a stove

$7(70 \%)$

Using lighter to light candles/incense, burning candles 7 (70\%)

Campfires

Burning trash, tires, couches (other objects)

Frequency (\%)

Playing with fireworks

$6(60 \%)$

$6(60 \%)$

$5(50 \%)$

Smoking (cigarettes)

$4(40 \%)$

Curling hair, straightening hair

$4(40 \%)$

Leaving appliances plugged in and/or turned on

$3(30 \%)$

$3(30 \%)$

Blowing things up for fun

$3(30 \%)$

Behavioral Beliefs ("What are the advantages/disadvantages of engaging in fire behaviors? What sort of outcomes do you expect when engaging in fire behaviors?”)

Fun, relaxing, enjoyable

Get burned, hurt yourself, get scarred

$10(100 \%)$

$9(90 \%)$

$4(40 \%)$

$3(30 \%)$

Get food (from cooking)

$3(30 \%)$

Burn your house down

$3(30 \%)$

Peers may think you are not cool

$3(30 \%)$

Normative Beliefs ("Who would approve/disapprove of you engaging in fire behaviors?”)

Parents

Peers, friends

Siblings

Police and firemen

Elderly people

Friend's parents

Relatives

Principals, teachers
$8(80 \%)$

5 (50\%)

$3(30 \%)$

$3(30 \%)$

3 (30\%)

$3(30 \%)$

2 (20\%)

2 (20\%) 
Control Beliefs ("What would make it easier/harder for you to engage in fire behaviors? What might influence to engage/not engage in fire behaviors?”)

Right weather conditions/season

$6(60 \%)$

Having necessary resources

Having friends who want to, peer pressure

$3(30 \%)$

Parents who disapprove

$3(30 \%)$

Parties, holidays, get togethers

$3(30 \%)$

Seeing somebody else who has been burned

$3(30 \%)$

Attitude towards Behavior ("I think engaging in fire behaviors would be...”)

Fun $6(60 \%)$

Dangerous, risky, scary $4(40 \%)$

Amazing, exciting, cool

$4(40 \%)$

Stupid, deadly

$2(20 \%)$

Enjoyable

$2(20 \%)$ 
Table 4

Fire and Burn Injury Safety Questionnaire (FBISQ) Item-to-Total Correlations

\begin{tabular}{lc}
\hline Item & $r$ \\
\hline How often should you check smoke detectors? & 0.27 \\
Name one kitchen safety tip. & 0.21 \\
What are the four steps to using a fire extinguisher? & 0.18 \\
How should you safely refuel your lawnmower? & 0.25 \\
How many feet away should you keep space heater? & 0.21 \\
If your clothes catch on fire, what should you do? & 0.42 \\
How many escape routes should you have from each room? & 0.22 \\
How should you put out a grease fire? & -0.02 \\
What could you do to safely start the fire? & 0.34 \\
What temperature should you/your parent set hot water heater? & 0.24 \\
What is first thing you should do to take care of (scald) burn? & 0.39 \\
\hline
\end{tabular}


Table 5

TPB Questionnaire Cronbach Alphas and Item-to-Total Correlations

\begin{tabular}{lr}
\hline Subscale & Cronbach alpha \\
\hline & \\
Behavioral Intentions & 0.91 \\
I think I might engage in fire behaviors... & 0.76 \\
I want to engage in a fire behavior... & 0.85 \\
I plan or intend to engage in a fire behavior... & 0.84 \\
& \\
Attitudes toward Behavior & \\
I think engaging in a fire behavior is scary/calming. & 0.90 \\
I think engaging in a fire behavior is good/bad. & 0.70 \\
I think engaging in a fire behavior is enjoyable/not enjoyable. & 0.81 \\
I think engaging in a fire behavior is stupid/smart. & 0.76 \\
I think engaging in a fire behavior is fun/boring. & 0.72 \\
I think engaging in a fire behavior is dangerous/safe. & 0.64
\end{tabular}

Subjective Norms

Most people who are important to me...

It is expected of me that I engage in fire behaviors.

0.76

I feel pressure from others to engage in fire behaviors.

0.50

People who are important to me want me to...

Perceived Behavioral Control

If I wanted to, it would be easy for me to engage...

The decision to engage in fire behaviors is entirely up to me*

Whether I engage in fire behaviors is entirely up to me.

Behavioral Beliefs and Outcome Evaluations

If I engage in fire behavior, I will get burned.

0.35

If I engage in fire behavior, I will have a lot of fun.

If I engage in fire behavior, I will fit in with my peers.

If I engage in fire behavior, I will catch my house on fire. 
Catching my house on fire is

Getting in trouble with my parents is

Proving that I am tough is

Normative Beliefs and Motivation to Comply

0.80

My parents would __ of me engaging in fire behaviors.

0.58

My siblings would of me engaging in fire behaviors.

0.63

My friends would of me engaging in fire behaviors.

0.52

My friends' parents would __ of me engaging in fire behaviors.

0.60

My teachers/principals would __ of me engaging in fire behaviors.

0.49

The police/fire department would __ of me engaging in fire behaviors.

0.59

I do what my parents think I should do.

0.38

I do what my siblings think I should do.

0.50

I do what my friends think I should do.

0.44

I do what my friends' parents think I should do.

0.31

I do what my teachers/principals think I should do.

0.31

I do what the police/fire department think I should do.

0.06

Control Beliefs and Perceived Power

0.72

...I have friends who also want to engage...

0.53

...I have the right resources...

0.59

My parents approve of me engaging in fire behaviors.

0.36

....the weather is warmer.

0.46

....I think about people who have burn injuries.

$-0.19$

Having friends who want to engage in fire behaviors makes it

0.53

Having the right resources makes it

0.41

Having parents who approve of me

0.50

When the weather is warmer, it makes it to engage...

0.50

Seeing someone who has been burned makes it

0.26

* Item dropped from final TPB Questionnaire. 
Table 6

Means and Standard Deviations of Phase 3 Study Variables

\begin{tabular}{|c|c|c|c|c|}
\hline Measure & $M$ & $S D$ & Range & Cronbach Alpha \\
\hline TPB-Intentions & 4.79 & 2.72 & $0-9$ & 0.92 \\
\hline TPB-Attitude toward Behavior & 8.45 & 3.59 & $0-18$ & 0.92 \\
\hline TPB-Subjective Norms & 2.84 & 2.17 & $0-8$ & 0.82 \\
\hline TPB-Perceived Behavioral Control & 4.28 & 1.42 & $0-6$ & 0.68 \\
\hline BASC-2: Anxiety* & 15.83 & 9.40 & $0-78$ & \\
\hline BASC-2: Sensation Seeking* & 11.67 & 4.62 & $1-26$ & \\
\hline BASC-2: Hyperactivity* & 7.04 & 4.34 & $0-42$ & \\
\hline BASC-2: Attention Problems* & 8.10 & 5.44 & $0-41$ & \\
\hline Fire and Burn Injury Safety Questionnaire & 34.90 & 3.68 & $22-43$ & 0.48 \\
\hline Parental Solicitation & 25.66 & 11.48 & $0-56$ & 0.85 \\
\hline Child Self-Disclosure & 21.16 & 11.90 & $0-76$ & 0.86 \\
\hline Parental Behavioral Control & 31.68 & 10.83 & $1-56$ & 0.89 \\
\hline Rebellious Behavior & 0.26 & 0.42 & $0-3.4$ & 0.86 \\
\hline Reckless Behavior & 0.77 & 0.77 & $0-4$ & 0.55 \\
\hline
\end{tabular}


Table 7

Means and Standard Deviations of BASC-2 Standard Scores

\begin{tabular}{lccc}
\hline BASC-2 Subscale & $M$ & $S D$ & Range \\
\hline Anxiety & 56.47 & 13.29 & $32-86$ \\
Sensation Seeking & 50.00 & 10.60 & $26-79$ \\
Hyperactivity & 52.81 & 10.78 & $33-84$ \\
Attention Problems & 51.20 & 11.33 & $34-82$ \\
\hline
\end{tabular}

Note: Mean for standard scores $=50 ; S D=10$. 
Table 8

Bivariate Associations among Study Variables

\begin{tabular}{|c|c|c|c|c|c|c|c|c|c|c|c|c|c|c|c|c|c|}
\hline & Age & $\begin{array}{l}\text { TPB- } \\
\text { Att }^{\mathrm{b}}\end{array}$ & $\begin{array}{l}\text { TPB- } \\
\text { Norm }^{\mathrm{c}}\end{array}$ & $\begin{array}{l}\text { TPB- } \\
\text { PBC }^{\text {d }}\end{array}$ & SES & Gender & $\begin{array}{l}\text { Geo } \\
\text { Loc }^{f}\end{array}$ & $\begin{array}{l}\text { BASC- } \\
\text { Anx } x^{g}\end{array}$ & $\begin{array}{l}\text { BASC- } \\
\text { Sen Seek }\end{array}$ & $\begin{array}{l}\text { BASC- } \\
\text { Hyp }^{\mathrm{i}}\end{array}$ & $\begin{array}{l}\text { BASC- } \\
\text { Attn }^{j}\end{array}$ & FBISQ $^{k}$ & $\begin{array}{l}\text { Solicitatio } \\
\mathrm{n}^{k}\end{array}$ & Self-dis ${ }^{1}$ & $\begin{array}{l}\text { Beh } \\
\text { Control }^{\mathrm{m}}\end{array}$ & $\begin{array}{l}\text { Rebell } \\
\text { Beh }^{n}\end{array}$ & $\begin{array}{l}\text { Reck } \\
\text { Beh }^{0}\end{array}$ \\
\hline TPB-Intent $^{\mathrm{a}}$ & .03 & $.59^{* *}$ & $.46^{* *}$ & $.30^{* *}$ & .07 & .10 & -.02 & .03 & $.28^{* *}$ & $.14^{*}$ & $.14^{*}$ & -.04 & .04 & -.04 & -.04 & $.40^{* *}$ & $.22^{* *}$ \\
\hline Age & & .11 & .02 & .12 & $.14^{*}$ & -.07 & $-.44 * *$ & -.06 & .11 & -.01 & .03 & .03 & -.05 & -.06 & $-.31 * *$ & $.27 * *$ & $.49^{* *}$ \\
\hline TPB-Att ${ }^{b}$ & & & $.53 * *$ & $.40^{* *}$ & .12 & $.25^{* *}$ & -.12 & -.10 & $.32 * *$ & $.18^{* *}$ & .07 & -.01 & -.08 & -.10 & -.14 & $.31 * *$ & $.21^{* *}$ \\
\hline TPB-Norm ${ }^{c}$ & & & & $.22 * *$ & $.17^{*}$ & .12 & -.03 & .09 & $.18^{* *}$ & $.21^{* *}$ & $.16^{*}$ & .05 & -.02 & -.01 & -.11 & $.21^{* *}$ & .09 \\
\hline TPB-PBC $^{\mathrm{d}}$ & & & & & .08 & .10 & -.06 & $.17^{*}$ & $.32 * *$ & $.25 * *$ & $.22 * *$ & $-.13 *$ & .10 & -.08 & $-.23^{* *}$ & $.37 * *$ & $.23^{* *}$ \\
\hline SES & & & & & & $.15^{*}$ & $-.15^{*}$ & .01 & .10 & .07 & .01 & .11 & .08 & .05 & .07 & -.11 & -.00 \\
\hline Gender & & & & & & & -01 & $-.34 * *$ & .08 & -.09 & $-.15^{* *}$ & .07 & -.07 & -.08 & .09 & .12 & -.07 \\
\hline Geo Loc ${ }^{e}$ & & & & & & & & .09 & -.08 & .06 & $.16^{*}$ & $-.17 *$ & .06 & -.03 & .11 & -.05 & $-.33^{* *}$ \\
\hline BASC-Anx ${ }^{f}$ & & & & & & & & & .13 & $.52 * *$ & $.61^{* *}$ & -.05 & .07 & .01 & -.04 & .08 & .03 \\
\hline BASC-Sen Seek ${ }^{g}$ & & & & & & & & & & $.43^{* *}$ & $.21^{* *}$ & -.06 & $.17 *$ & .03 & -.08 & $.41^{* *}$ & $.31 * *$ \\
\hline BASC-Hyp ${ }^{\text {h }}$ & & & & & & & & & & & $.65 * *$ & -.01 & .07 & .06 & .02 & .11 & .04 \\
\hline BASC-Attn ${ }^{\mathrm{i}}$ & & & & & & & & & & & & -.08 & -.03 & -.09 & -.09 & $.16^{*}$ & .03 \\
\hline FBISQ ${ }^{j}$ & & & & & & & & & & & & & -.08 & .07 & -.01 & -.09 & .04 \\
\hline Solicitation $^{\mathrm{k}}$ & & & & & & & & & & & & & & $.67 * *$ & $.47 * *$ & .07 & .04 \\
\hline Self-dis ${ }^{1}$ & & & & & & & & & & & & & & & $.37 * *$ & -.06 & .04 \\
\hline Beh Control $^{\mathrm{m}}$ & & & & & & & & & & & & & & & & $-.36 * *$ & $-.23 * *$ \\
\hline Rebell Beh ${ }^{\mathrm{n}}$ & & & & & & & & & & & & & & & & & $.51^{* *}$ \\
\hline $\operatorname{Reck}^{B e h}{ }^{0}$ & & & & & & & & & & & & & & & & & \\
\hline
\end{tabular}

${ }^{\mathrm{a}}$ TPB Behavioral Intentions; ${ }^{\mathrm{b}}$ TPB Attitude towards Behavior; ${ }^{\mathrm{c}}$ TPB Subjective Norms; ${ }^{\mathrm{d}}$ TPB Perceived Behavioral Control; ${ }^{\mathrm{e}}$ Geographic Location; ${ }^{\mathrm{f}}$ BASC-2

- Anxiety Subscale; ${ }^{\mathrm{g}}$ BASC-2 - Sensation Seeking Subscale; ${ }^{\mathrm{h}}$ BASC-2 - Hyperactivity Subscale; ${ }^{\mathrm{i}}$ BASC-2 - Attention Problems Subscale; ${ }^{\mathrm{j}}$ Fire and Burn 
Injury Safety Questionnaire; ${ }^{\mathrm{k}}$ Parental Solicitation; ${ }^{1}$ Child Self-Disclosure; ${ }^{\mathrm{m}}$ Parental Behavioral Control; ${ }^{\mathrm{n}}$ Adolescent Risk-Taking Questionnaire - Rebellious

Behavior Subscale; and ${ }^{\circ}$ Adolescent Risk-Taking Questionnaire - Reckless Behavior Subscale. 
Table 9

Multiple Regression Analysis Predicting Fire-Risk Behavioral Intentions from TPB

Components

\begin{tabular}{|c|c|c|c|c|c|}
\hline Predictor & & B & Std. Error & $\beta$ & $\mathrm{t}$ \\
\hline TPB-Attitudes & & .350 & .052 & .485 & $6.70 * *$ \\
\hline TPB-Subjective Norms & & .229 & .081 & .175 & $2.83 * *$ \\
\hline TPB-Perceived Behavioral Control & & .127 & .114 & .063 & 1.11 \\
\hline$F$ & 41.34 & & & & \\
\hline Total $R^{2}$ & .377 & & & & \\
\hline$n$ & 209 & & & & \\
\hline
\end{tabular}




\section{Table 10}

Bivariate Associations among TPB Questionnaire Subscales

\begin{tabular}{|c|c|c|c|c|}
\hline Subscale & $\begin{array}{l}\text { Behavioral } \\
\text { Intentions }\end{array}$ & $\begin{array}{c}\text { Attitude towards } \\
\text { Behavior }\end{array}$ & $\begin{array}{c}\text { Subjective } \\
\text { Norms }\end{array}$ & $\begin{array}{c}\text { Perceived } \\
\text { Behavioral } \\
\text { Control }\end{array}$ \\
\hline $\begin{array}{l}\text { Behavioral Beliefs } \\
\text { If I engage in fire behavior, I will get burned. } \\
\text { If I engage in fire behavior, I will have a lot of fun. } \\
\text { If I engage in fire behavior, I will fit in with my peers. } \\
\text { If I engage in fire behavior, I will catch my house on fire. } \\
\text { If I engage in fire behavior, I will get in trouble with parents. } \\
\text { If I engage in fire behavior, I will prove that I am tough... }\end{array}$ & $\begin{array}{l}-.33 * * \\
.59 * * \\
.33 * * \\
-.36 * * \\
-.37 * * \\
.12\end{array}$ & $\begin{array}{l}-.46 * * \\
.58 * * \\
.27 * * \\
-.42 * * \\
-.52 * * \\
.10\end{array}$ & & \\
\hline $\begin{array}{l}\text { Normative Beliefs } \\
\text { My parents would __ of me engaging in fire behaviors. } \\
\text { My siblings would__of me engaging in fire behaviors. } \\
\text { My friends would __ of me engaging in fire behaviors. } \\
\text { My friends' parents would _ of me engaging in fire behaviors. } \\
\text { My teachers/principals would __ of me engaging in fire behaviors. } \\
\text { The police/fire department would __ of me engaging in fire } \\
\text { behaviors. }\end{array}$ & $\begin{array}{l}.52 * * \\
.39 * * \\
.54 * * \\
.47^{* *} \\
.33^{* *} \\
.22^{* *}\end{array}$ & & $\begin{array}{l}.56^{* *} \\
.34^{* *} \\
.45^{* *} \\
.57^{* *} \\
.43^{* *} \\
.40^{* *}\end{array}$ & \\
\hline $\begin{array}{l}\text { Control Beliefs } \\
\text {...I have friends who also want to engage... } \\
\text {...I have the right resources... } \\
\text { My parents approve of me engaging in fire behaviors. } \\
\text {....the weather is warmer. } \\
\text {...I think about people who have burn injuries. }\end{array}$ & $\begin{array}{l}.53^{* *} \\
.49^{* *} \\
.45^{* *} \\
.21^{* *} \\
-.19^{* *}\end{array}$ & & & $\begin{array}{l}.32^{* *} \\
.43^{* *} \\
.28^{* *} \\
.23^{* *} \\
-.19^{* *}\end{array}$ \\
\hline
\end{tabular}

$* p<.05 ; * * p<.01$ 


\section{Table 11}

Hierarchical Regression Analysis Predicting Fire-Risk Behavioral Intentions from TPB

Components while Controlling for Age, SES, Geographic Location, and Gender

\begin{tabular}{|c|c|c|c|c|c|}
\hline Predictor & $\Delta R^{2}$ & B & Std. Error & $\beta$ & $\mathrm{t}$ \\
\hline Step 1 & .000 & & & & \\
\hline Age & & -.008 & .177 & -.003 & -.046 \\
\hline Step 2 & .015 & & & & \\
\hline Age & & .011 & .198 & .004 & .055 \\
\hline SES & & .005 & .017 & .021 & .294 \\
\hline Geographic Location & & .058 & .439 & .011 & .133 \\
\hline Gender & & .709 & .431 & .119 & 1.65 \\
\hline Step 3 & $.365^{* *}$ & & & & \\
\hline Age & & -.107 & .160 & -.043 & -.669 \\
\hline SES & & -.008 & .014 & -.035 & -.593 \\
\hline Geographic Location & & .213 & .351 & .039 & .607 \\
\hline Gender & & -.225 & .358 & -.038 & -.628 \\
\hline TPB-Attitudes & & .366 & .056 & .490 & $6.56^{* *}$ \\
\hline TPB-Subjective Norms & & .211 & .085 & .169 & $2.48 * *$ \\
\hline TPB-Perceived Behavioral Control & & .141 & .117 & .075 & 1.20 \\
\hline$F$ & 17.01 & & & & \\
\hline Total $R^{2}$ & .380 & & & & \\
\hline$n$ & 202 & & & & \\
\hline
\end{tabular}




\section{Table 12}

Hierarchical Regression Analysis Predicting Fire-Risk Behavioral Intentions from TPB

Components while Controlling for BASC-2 Subscales

\begin{tabular}{|c|c|c|c|c|c|}
\hline Predictor & $\Delta R^{2}$ & B & Std. Error & $\beta$ & $\mathrm{t}$ \\
\hline Step 1 & $.110^{* *}$ & & & & \\
\hline BASC-2: Anxiety & & -.017 & .026 & -.053 & -.676 \\
\hline BASC-2: Sensation Seeking & & .171 & .043 & .296 & $3.95^{* *}$ \\
\hline BASC-2: Hyperactivity & & -.013 & .066 & -.017 & -.191 \\
\hline BASC-2: Attention Problems & & .083 & .050 & .149 & 1.67 \\
\hline Step 2 & $.303^{* *}$ & & & & \\
\hline BASC-2: Anxiety & & .015 & .022 & .046 & .688 \\
\hline BASC-2: Sensation Seeking & & .076 & .038 & .131 & $2.01 *$ \\
\hline BASC-2: Hyperactivity & & -.072 & .054 & -.097 & -1.32 \\
\hline BASC-2: Attention Problems & & .044 & .041 & .079 & 1.07 \\
\hline TPB-Attitudes & & .345 & .054 & .467 & $6.42^{* *}$ \\
\hline TPB-Subjective Norms & & .235 & .081 & .189 & $2.88 * *$ \\
\hline TPB-Perceived Behavioral Control & & .059 & .119 & .033 & .493 \\
\hline$F$ & 18.86 & & & & \\
\hline Total $R^{2}$ & .413 & & & & \\
\hline$n$ & 196 & & & & \\
\hline
\end{tabular}


Table 13

Hierarchical Regression Analysis Predicting Fire-Risk Behavioral Intentions from TPB Components while Controlling for Fire and Burn Knowledge

\begin{tabular}{|c|c|c|c|c|c|}
\hline Predictor & $\Delta R^{2}$ & B & Std. Error & $\beta$ & $\mathrm{t}$ \\
\hline Step 1 & .001 & & & & \\
\hline FBISQ $^{a}$ & & -.025 & .051 & -.035 & -.504 \\
\hline Step 2 & $.377 * *$ & & & & \\
\hline FBISQ $^{a}$ & & -.026 & .041 & -.035 & -.630 \\
\hline TPB-Attitudes & & .350 & .052 & .466 & $6.69 * *$ \\
\hline TPB-Subjective Norms & & .233 & .082 & .187 & $2.86^{* *}$ \\
\hline TPB-Perceived Behavioral Control & & .116 & .115 & .061 & 1.01 \\
\hline$F$ & 31.01 & & & & \\
\hline Total $R^{2}$ & .378 & & & & \\
\hline$n$ & 209 & & & & \\
\hline
\end{tabular}

$* p<.05 ; * * p<.01$

${ }^{\mathrm{a}}$ Fire and Burn Injury Safety Questionnaire. 


\section{Table 14}

Hierarchical Regression Analysis Predicting Fire-Risk Behavioral Intentions from TPB Components while Controlling for Age and Parental Monitoring

\begin{tabular}{|c|c|c|c|c|c|}
\hline Predictor & $\Delta R^{2}$ & B & Std. Error & $\beta$ & $\mathrm{t}$ \\
\hline Step 1 & .000 & & & & \\
\hline Age & & -.071 & .186 & -.029 & -.379 \\
\hline Step 2 & .007 & & & & \\
\hline Age & & -.126 & .199 & -.052 & -.634 \\
\hline Parental Solicitation & & -.005 & .027 & -.020 & -.180 \\
\hline Child Self-Disclosure & & .010 & .026 & .041 & .393 \\
\hline Parental Behavioral Control & & -.022 & .023 & -.089 & -.932 \\
\hline Step 3 & $.352 * *$ & & & & \\
\hline Age & & -.169 & .162 & -.070 & -1.05 \\
\hline Parental Solicitation & & .002 & .023 & .007 & .078 \\
\hline Child Self-Disclosure & & -.003 & .021 & -.012 & -.134 \\
\hline Parental Behavioral Control & & .011 & .020 & .044 & .538 \\
\hline TPB-Attitudes & & .285 & .065 & .376 & $4.40 * *$ \\
\hline TPB-Subjective Norms & & .314 & .098 & .250 & $3.19 * *$ \\
\hline TPB-Perceived Behavioral Control & & .206 & .134 & .111 & 1.53 \\
\hline$F$ & 13.23 & & & & \\
\hline Total $R^{2}$ & .360 & & & & \\
\hline$n$ & 173 & & & & \\
\hline
\end{tabular}


Table 15

Hierarchical Regression Analysis Predicting Fire-Risk Behavioral Intentions from TPB

Components while Controlling for Age, Rebellious Behavior, and Reckless Behavior

\begin{tabular}{|c|c|c|c|c|c|}
\hline Predictor & $\Delta R^{2}$ & $\mathrm{~B}$ & Std. Error & $\beta$ & $\mathrm{t}$ \\
\hline Step 1 & .001 & & & & \\
\hline Age & & -.061 & .177 & -.025 & -.343 \\
\hline Step 2 & $.118^{* *}$ & & & & \\
\hline Age & & -.389 & .195 & -.158 & $-1.99 *$ \\
\hline Rebellious Behavior & & 1.26 & .295 & .316 & $4.25^{* *}$ \\
\hline Reckless Behavior & & .866 & .706 & .102 & 1.23 \\
\hline Step 3 & $.303^{* *}$ & & & & \\
\hline Age & & -.346 & .160 & -.141 & $-2.16^{*}$ \\
\hline Rebellious Behavior & & .705 & .256 & .177 & $2.76^{* *}$ \\
\hline Reckless Behavior & & .239 & .585 & .028 & .410 \\
\hline TPB-Attitudes & & .317 & .055 & .427 & $5.73^{* *}$ \\
\hline TPB-Subjective Norms & & .265 & .085 & .219 & $3.12 * *$ \\
\hline TPB-Perceived Behavioral Control & & -.037 & .117 & -.020 & -.314 \\
\hline$F$ & 22.73 & & & & \\
\hline Total $R^{2}$ & .423 & & & & \\
\hline$n$ & 194 & & & & \\
\hline
\end{tabular}


Figure 1

Theory of Planned Behavior

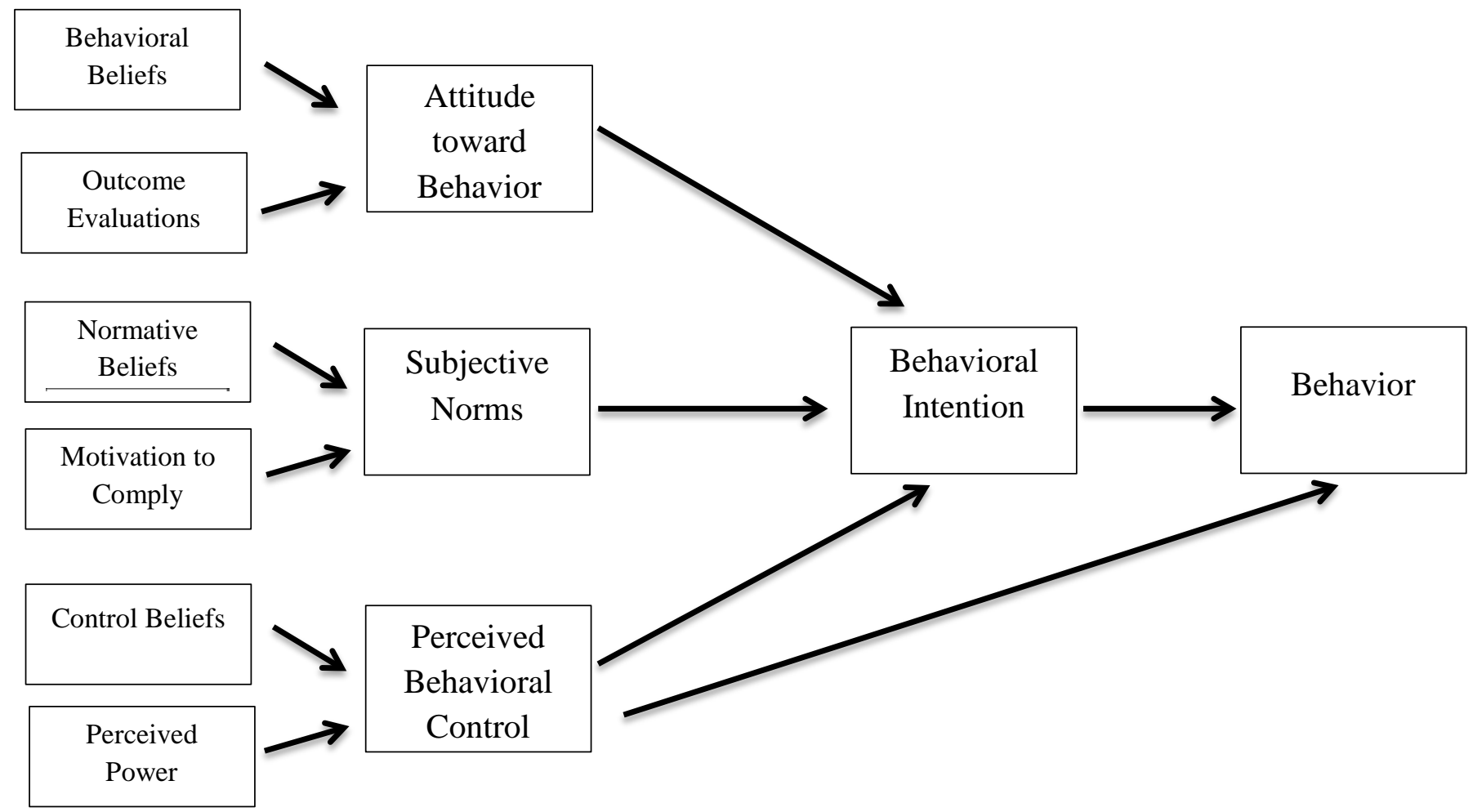

